\title{
Giving In: Chronic Pain, BDSM, and Crip/Queer Utopia
}

by

\author{
Rachel Jobson
}

A thesis submitted to the Faculty of Graduate and Postdoctoral Affairs in partial fulfillment of the requirements for the degree of

Master of Arts
in

Women's and Gender Studies

Carleton University

Ottawa, Ontario

(C) 2020, Rachel Jobson 


\begin{abstract}
This thesis considers whether people living with chronic pain can reimagine their relationship with pain and challenge structural narratives that frame lives lived in pain as less worth living through participation in BDSM (bondage, discipline/Domination, submission/sadism, masochism). Using feminist ethnography shaped by cripistemology, I use crip theory to consider how chronic pain might be experienced differently in a context where interdependence is valued. I argue that by connecting work around queer temporality and José Esteban Muñoz's theory of utopia to BDSM practices it is possible to think pain otherwise. Radical BDSM practices challenge the hermeneutical injustice of chronic pain by allowing people in pain to express it, share it with others, and be fully seen, while also encouraging interdependence. It is through this process that BDSM is one example of queer utopia: a space of potentiality where different futures and perspectives on pain can be imagined outside of straight/capitalist time.
\end{abstract}




\section{Acknowledgements}

I am so grateful to my supervisors Kelly Fritsch and Patrizia Gentile for their incredible guidance throughout this entire process. Their thoughtful feedback, critical questions, and unwavering support made me a better scholar and writer. I am also immensely grateful to my committee: Alyson Patsavas (External), Ummni Khan (Internal), and Katie Bausch (Chair) for their insightful questions and meaningful engagement with my work throughout the defence process. Thank you to my fellow MA students across all cohorts in the Women's and Gender Studies Department, as well as the other faculty I have had the privilege to learn from over the past two years. Alexis Shotwell and our Thursday writing group have provided invaluable support, guidance and feedback throughout the process of writing this thesis. I would be remiss if I don't also mention Lana Keon, our amazing departmental administrator who kept me on track with logistics and paperwork and was always available with hugs and candy whenever necessary.

Outside of academia, I am thankful for my family and friends who never questioned and always supported my decision to leave a stable career and go to grad school in my 30s. I especially could not have completed this without the support of my partner Chris, who made sure I had nutritious meals every night, proofread many (long) papers, edited every grant application and has been my constant cheerleader.

Last, but absolutely not least, thank you to my participants and all of the crip/queer knowledge producers who have shaped this work and been at the heart of so many critical, radical movements. I finished this thesis in the midst of the COVID-19 pandemic and in the face of eugenicist discourses over who does and does not deserve access to life-saving care. Now more than ever, crip knowledge gives me hope for different futures. 


\section{Table of Contents}

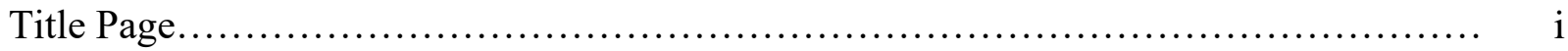

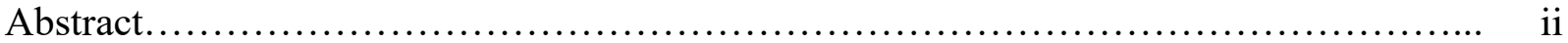

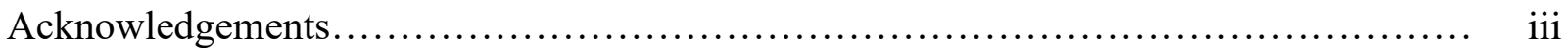

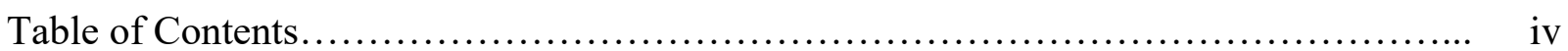

Chapter One: Introduction............................................... 1

Theoretical Framework................................................ 3

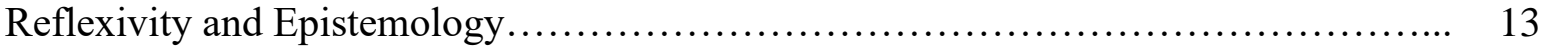

Methodology............................................................... 17

Chapter Two: The Complexities of Pain, Invisibility and Diagnosis................. 27

A Brief Autobiography of Chronic Pain.................................... 27

Theories of Pain ....................................................... 34

Hermeneutical Injustice................................................. 40

Chapter Three: Critical Futurity, BDSM and the Disabled Body $\ldots \ldots \ldots \ldots \ldots \ldots \ldots \ldots \ldots \ldots . \quad 54$

Understandings of Pain in BDSM ........................................... 55

BDSM and Disabled Sexuality ......................................... 56

Desiring Disability and Queer Utopias.................................... 62

Thinking Pain Otherwise ............................................... 74

Conclusion............................................................... 82

References.............................................................. 87

Appendix A: Interview Guide................................................ 96 


\section{Chapter One: Introduction}

What would it take for a river that polluted to be loved? What would it take for us to know our bodies beautiful?

To wash them clean?

Naw-not washed clean.

What if our working-class, fucked up, chronically-ill, sick, survivor bodies were beautiful just like they are?

Beautiful like the fields of weed trees that would bust through the cement of every vacant lot in my hometown 5 weeks after the store that was in it closed?

What would it take for a river that polluted to be loved?

For cement to bomb open?

For my body, for your body, to come back from being washed away?

When I flare or I get sick I go to my bed and I fuck myself so hard.

I close all the doors and I fuck myself for hours and hours and hours.

Sometimes I fuck myself, read library books, and check Facebook all at the same time.

My cock in my pussy and my vibrator on my clit stays there forever, sometimes I make myself come like no one else. Sometimes I just hover there in that place before coming for hours, and there is no pain, just me being the slut that kept me alive.

When I fuck myself I think of my best friend in rural North Carolina with Lyme disease getting caned by her Daddy boyfriend when she's taken enough oxycontin for her pain. I think about of all of us fucking ourselves in our beds when we're sick. When we're not. I think about how lucky I am to still get to come.

When I fuck myself, I think: they didn't wash this away. Filthy, abandoned as not making them any money anymore. Gorgeous. Shaky hipped. Coming. Gorgeous. Wriggling ass down in bed. Slut. They can't put this shit in no culvert. We didn't go anywhere. Even if you didn't visit. This source. She unquenchable. She here after all the bullshit done. She keeps coming. I surrender to it. We right here. All it takes to love a river that polluted, a body this full of story, is to surrender, to love it.

I give in. ${ }^{1}$ (Piepzna-Samarasinha, 2010)

Disabled writer and activist Leah Lakshmi Piepzna-Samarasinha challenges us to consider the radical possibility of giving in. Western cultural norms frame sick, pained, and disabled lives as lives that are less worth living and less worth protecting, but despite these narratives, "they didn't

\footnotetext{
${ }^{1}$ This is a transcript of a spoken word poem performed by Leah Lakshmi Piepzna-Samarasinha at a Sins Invalid performance in 2009. For the full impact of the piece, the live performance can be seen at: https://www.youtube.com/watch? $v=t j 9 E e Q s h 4 L k$. The transcript included here is a direct transcript of the words from that specific reading of the poem, and therefore does not exactly match the original words of the poem that are transcribed below the linked video.
} 
wash this away" (Piepzna-Samarasinha, 2010). Chronic pain and illness are often understood as failure: failure to overcome, failure to heal, failure to be productive and contribute to capitalist society. Challenging the repudiation of failure, Piepzna-Samarasinha embraces giving in to pain, framing sick, pained, survivor bodies as whole and worthy of pleasure and connection. In Piepzna-Samarasinha's conception, giving in is not the same as giving up. Giving in involves embracing the complexity of the suffering body and challenging systems of oppression like capitalism and compulsory able-bodiedness that render lives lived in pain as less worth living. It involves finding moments of connection, pleasure, and interdependence outside of capitalist straight time. This understanding of failure can become a form of queer utopia, one that disrupts normative structures and embraces the possibility of the horizon, a term used by José Esteban Muñoz to describe and explain queer theories of hope and utopia. These moments of connection can be found in many places, but this thesis will consider the potential of BDSM (bondage, discipline/Domination, submission/sadism, masochism) (Weiss, 2011) as a space of interdependence and queer utopia for people with chronic pain. Despite the increasing mainstream cultural engagement with chronic pain and kink, including first-person accounts on blogs, online magazines, and social media over the past number of years, there remains a lack of academic research that expands the salient possibilities of kink practices for people with chronic pain. The primary objective of my work is to establish whether people living with chronic pain can reimagine their relationship with pain and challenge structural and social narratives that frame lives lived in pain as less worth living through their participation in BDSM. Using queer feminist ethnography, ${ }^{2}$ I draw on crip theory and cripistemology to consider how chronic pain might be experienced differently in a context where interdependence is valued. I argue that by

\footnotetext{
${ }^{2}$ Specifically, two in-depth loosely-structured interviews, ethnographic content analysis of seven first-person online narratives, and autoethnography.
} 
connecting existing work around queer temporality and utopia to BDSM practices through the lens of crip theory, it is possible to imagine different disability futures that resist normalization, flattening, or depoliticizing forces.

\section{Theoretical Framework}

Inspired by feminist and queer theory's rejection of normativity, crip theory seeks to disrupt narrow conceptions of disability that are often pathologizing, limiting, and heteronormative. By challenging the unmarked categories of compulsory able-bodiedness and compulsory heterosexuality, crip theory presents new ways of living that resist neoliberal capitalism as the central organizing structure of our lives. One of the challenges in any discussion of disability is defining who is disabled. As Alison Kafer (2003) argues, it is dangerous to suggest that disabled implies a unified group of people with universally shared experiences. Within crip theory, the idea that identity is not fixed is a core principle, therefore Simi Linton's (1998) succinct definition of disability is useful: “The question of who 'qualifies' as disabled is as answerable or as confounding as questions about any identity status. One simple response might be that you are disabled if you say you are" (p. 12). This definition is applicable to chronic pain as well. For the purposes of this research, I am focused on the lived experiences of people with chronic pain, and I am defining the parameters of that group as anyone who says they live with chronic pain ${ }^{3}$ regardless of diagnosis. It is also important to note here that while not all people with chronic pain identify as disabled, many do, and for my purposes existing

\footnotetext{
${ }^{3}$ Interview participants were required to have lived with chronic pain for at least 6 months, but this was to ensure that they had sufficient experience with the overlap between chronic pain and their BDSM practices to provide meaningful answers to the interview questions.
} 
literature about disability will be used in a context that includes chronic pain as a form of disability.

Part of crip theory is the idea that there is pride or desire within the identity of disability. Robert McRuer (2016) argues that while "disabled" has started to reclaim this sense of pride, "crip" takes it further: "The flamboyant defiance of "crip" ties it to models of disability that are more culturally generative (and politically radical) than a merely reformist social model” (p. 121). In other words, "crip" is seen as a direct response to the social model of disability, which was in turn a response to the medical model of disability. While the social model imagines disability as a social problem that can be resolved through normalizing disability and shifting attitudes around accessibility and inclusion, and the medical model sees disability as pathology to be cured at all costs, crip theory engages with both the social and medical models to frame disability as a desirable form of difference that can be productively disruptive. With this understanding of how crip has been reclaimed as a positive identity, we can look at what crip theory contains as its core principles, which includes a rejection of compulsory able-bodiedness and normativity more broadly, the idea that queerness and disability are directly linked and dependent on each other, resistance to neoliberal capitalism, and radical accessibility.

In order to understand compulsory able-bodiedness, it is important to first understand the feminist principle it is based on, which is compulsory heterosexuality. Formally introduced by feminist writer Adrienne Rich (1980), compulsory heterosexuality was a groundbreaking contribution to the literature of its time. The nature and the danger of compulsory heterosexuality is that "heterosexuality goes unquestioned because its alleged naturalness and normalcy place it beyond the realm of political analysis" (Kafer, 2003, p. 78). This inscribing of one identity (or non-identity) as normal allows all other identities to be considered only in relation to it, thus 
allowing them to be subjugated and considered a lower and lesser identity within a hierarchy. As McRuer (2010) points out, the idea behind compulsory heterosexuality was not a new idea and had a lengthy history in feminist scholarship. However, the tendency of feminists and queer theorists to ignore disability or include it only as an afterthought inspired the idea of compulsory able-bodiedness: "I would argue...that feminist and queer theories (and cultural theories generally) are not yet accustomed to figuring ability/disability into the equation, and thus this theory of compulsory able-bodiedness is offered as a preliminary contribution to that muchneeded conversation" (McRuer, 2010, p. 89). Kafer (2003) uses this concept to develop the framework of compulsory able-bodiedness further. She argues that feminists often write from a position of able-bodiedness that is left unexamined and therefore kept outside the realm of critical analysis.

In practice, compulsory able-bodiedness is enforced in two primary ways: through the use of physical force, and through the control of public consciousness (Kafer, 2003). The first manifests in violence against people with disabilities. One of the most egregious examples is the state-sanctioned program of coercive and forced sterilization of people with disabilities, which at its core seeks to mandate compulsory able-bodiedness by physically intervening in the ability of disabled people to pass on their genes, thus potentially creating more people with disabilities. This can also be seen in the standardized process of screening fetuses for disability in utero, giving pregnant people the opportunity to eliminate disability before birth (Kafer, 2003).

The second tactic is more insidious and involves the cultural messages and assumptions that frame able-bodiedness as the default and baseline for normal (Kafer, 2003). It is this definition of compulsory able-bodiedness that will feature most prominently in my work. For people with invisible disabilities who are not marked with the cultural trappings we associate 
with disability such as wheelchairs or a white cane, their disabled identity is erased unless they explicitly state they are disabled. This can result in lack of access to necessary services, limited support from friends and family, and isolation from the disability community (Kafer, 2003). People with invisible disabilities are often met with suspicion when they identify as disabled because "under a system of compulsory able-bodiedness, why would you identify as disabled if you can pass as an able-bodied person? Compulsory able-bodiedness renders such an identification problematic, suggesting that a disability identity is to be avoided at all costs" (Kafer, 2003, p. 80). Compulsory able-bodiedness also reinforces the narrative that all people with disabilities must desire a cure or wish to overcome their disability. "A system of compulsory able-bodiedness repeatedly demands that people with disabilities embody for [nondisabled] others an affirmative answer to the unspoken question, 'Yes, but in the end, wouldn't you rather be more like me?"' (McRuer, 2010, p. 93). All of these facets of compulsory able-bodiedness combine to create a normative structure in which disability is framed as tragic, and it is this framework that crip theory resists when it promotes claiming a crip identity with pride.

It is also important to note that compulsory able-bodiedness does not simply borrow the concept from compulsory heterosexuality, they are in fact interlocking systems of oppression that depend on each other for existence. At its core, crip theory is a framework that "has been deployed to resist the contemporary spectacle of able-bodied heteronormativity" (McRuer, 2006, p. 3). Therefore, one of the central concepts of crip theory is that queerness and disability are inextricably linked and must be considered intersectionally in all analyses of disability. "Queerness, due to its history of medicalization, threatens to disrupt the institution of ablebodiedness, while disability, because of its associations with deviance and perversity, threatens 
the boundaries of heterosexuality" (Kafer, 2003, p. 82). The importance of this connection becomes clear when we consider that the pressure to conform to normative structures can be further intensified for disabled people, and this can lead to disabled communities trying to distance themselves from queer or otherwise non-normative sexuality:

Because disabled people have been oppressed and discriminated against on the basis of their disabilities, many have wanted to appear "normal," "natural," or "healthy" in other aspects of their lives. Under compulsory heterosexuality, however, queer behaviors and desires are rendered as the complete opposite: abnormal, unnatural, and unhealthy. Thus, some people within disability communities have wanted to distance themselves from queers - particularly visibly marked queers - with disabilities. The larger culture's heterosexism and homophobia are thus reproduced within the disability community. (Kafer, 2003, p. 83)

This interplay between compulsory able-bodiedness and heteronormativity highlights the double marginalization that can occur for people with chronic pain or other disabilities that also embrace non-normative sexual practices. As a radical approach to disability and concepts of impairment, crip theory is well-suited to conceptualize approaches to pain that fall outside of normative systems and structures because it recognizes queerness and resistance to normalization as critical to transformative social justice.

Resistance to neoliberal capitalism is also foundational to crip theory:

The OED [Oxford English Dictionary] defines able-bodied redundantly and negatively as 'having an able body, i.e. one free from physical disability, and capable of the physical exertions required of it; in bodily health; robust.' Ablebodiedness, in turn, is defined vaguely as 'soundness of bodily health; ability to work; robustness'. (McRuer, 2010, p. 91, emphasis added)

The definition of able-bodied is therefore directly tied to the capacity (or lack of capacity) to participate in neoliberal capitalism as a productive labourer. It follows then that challenging capitalism as the central organizing structure of our lives and shifting focus away from 
productivity as the primary purpose of human life could dramatically shift our understandings of disability and impairment. For this reason, crip theory is inherently anti-capitalist.

McRuer states that crip theory emerged from the tradition of questioning the order of things, how things become naturalized, and how beliefs are embedded in larger economic and social systems that is common in cultural studies (McRuer, 2006). As it was inspired by the feminist and queer practice of challenging the invisibility of heterosexuality, crip theory is in some ways indebted to feminism for its origins but is also critical of the ways feminism has ignored or scapegoated disability. Poststructuralist thought posits that identity is fluid and that politics are experienced through embodiment (McRuer, 2006). This is also connected to the idea that identity is formed at least partially through social relations. However, feminism has often used problematic language when describing the idea of social relations and the ways they contribute to oppression. As Kafer highlights, Adrienne Rich was guilty of this in her writings on compulsory heterosexuality, as she referred to the way patriarchy "disables" women, a common choice of words among feminist writers:

In characterizing social relations as disabling, Rich participates in an extensive feminist tradition of using the concept of disability to critique patriarchy...she eclipses the possibility of seeing disability as anything other than a negative, regrettable characteristic that is to be avoided, distancing the disabled body from the female one. Disability appears only as the negative other. (Kafer, 2003, p. 84)

Further, while crip theory has emerged directly out of queer theory, this is not to argue that queer and crip theory have an entirely harmonious relationship. As Merri Lisa Johnson (2015) points out, "queer theorists cannot always be counted on to convey crip sensitivities, even when directly asked to do so" (p. 252). She builds on this by pointing out that in the relationship between queer 
theory and crip theory, illness and disability is often asked to do more to serve queer theory than they receive in return (Johnson, 2015).

A consistent critique of earlier understandings of disability such as the social modelwhich argues that impairment is more about social barriers than physical ones - is that they fail to account for embodied experiences like pain. By challenging normativity and more broadly conceptualizing disability, crip theory creates space for more nuanced and productive discussions of pain and embodiment. As Emma Sheppard (2018) argues, pain can be a useful tool for troubling notions of normal, because medical frameworks often frame pain in terms of normal and abnormal pain, and therefore thinking of and through those normal/abnormal distinctions around pain can reveal "the social constructions that underpin understandings of proper bodily function and control" (p. 59). In this conception, being in pain is imagined as abnormal, thus casting those with chronic pain as inherently outside normativity. By challenging compulsory able-bodiedness in the context of pain, it becomes possible to imagine scenarios where someone would choose to engage with pain in ways that feel positive or even erotic. This also re-centres the standpoint of the person living with pain (Sheppard, 2018). While it is important to consider the structural conditions that frame pain as abnormal, the embodied experience of pain and impairment can still present a challenge to both the social model and the idea of desiring disability:

Impairment is problematic for people who experience pain, illness, shortened lifespan or other factors. As a result, they may seek treatment to minimize these consequences and, in extreme circumstances, may no longer wish to live. It is vital not to assume that they are experiencing a kind of 'false consciousness' that if all the external disabling barriers were removed they would no longer feel like this. We need to ensure the availability of all the support and resources that an individual might need, whilst acknowledging that impairment can still be intolerable. (Crow, 2010, p. 133) 
This is a problem that is reckoned with by both Kafer (2003) and Alyson Patsavas (2014), who also point out that for people in pain or dealing with shortened life expectancies, severe fatigue, or other symptoms that have a significant impact on their lives, it can be possible to both take pride in the label of disability, while also wishing to treat their pain, or at least prevent it from getting worse:

Kafer's and Patsavas's willingness to delve into their own un-desires is rare. For all that feminist $\mathrm{DS}^{4}$ scholars unite personal, political, body, and mind, we rarely look closely at the possibility that some aspects of disabled bodymind are distinctly undesirable. And by 'aspects,' I don't mean the oppressive structures acting on those bodyminds, but rather, the bodyminds themselves. (Price, 2015, p. 276)

With this in mind, I turn to Kafer's political/relational model of disability, which expands on the concepts introduced above. Similar to the social model, the political/relational model recognizes that social systems and structures have a significant impact on the lives of disabled people, but the political/relational model challenges the distinction between impairment and disability that is favoured by the social model (Kafer, 2013). Under the social model, impairment refers to physical or mental limitations, while disability refers to social exclusions or access issues that are attributed to those impairments. The central argument is that impairments are not disabling themselves, but rather become disabling through social structures that fail to accommodate them. The political/relational model acknowledges the importance of addressing the social structures that make lives harder for disabled people, while also acknowledging that it is an oversimplification to suggest that people are only disabled by these same systems. As Kafer notes,

people with chronic illness, pain, and fatigue have been among the most critical of this aspect of the social model, rightly noting that social and structural

\footnotetext{
${ }^{4}$ For the purposes of this thesis, it's important to clarify that DS means "Disability Studies" in this sentence, and not Dominance/submission.
} 
changes will do little to make one's joints stop aching or to alleviate back pain. Nor will changes in architecture and attitude heal diabetes or cancer or fatigue. Focusing exclusively on disabling barriers as a strict social model seems to do, renders pain and fatigue irrelevant to the project of disability politics. (Kafer, 2013, p. 7)

This oversight is challenged by the political/relational model, which views medicalization from a more neutral stance, recognizing that it can be both an oppressive tool that can cause great harm, while also being a critical aspect of care for people who live with certain conditions. The political/relational model "neither opposes nor valorizes medical intervention... it recognizes the possibility of simultaneously desiring to be cured of chronic pain and to be identified and allied with disabled people" (Kafer, 2013, p. 6).

This is critical to acknowledge for the purposes of my research. While I am looking at how people seek out particular practices or communities that help them manage their pain outside of a medical context, I am wary of unintentionally suggesting that medical intervention holds no value to people living with pain. None of the research that follows is intended to suggest that people with chronic pain are letting down the cause of disability justice if they seek treatment, medical interventions, or cure for their pain. It is not intended to suggest that the solution to pain is ever as simple as a lifestyle or attitude adjustment, but rather intended to provide an understanding of the ways people living with pain make space to engage with that pain. It is not intended to be prescriptive; it draws attention to and theorizes the lived experiences of people in an imperfect system who are finding unique ways to manage their pain, often alongside medical interventions. This is in keeping with the political aspect of Kafer's political/relational model, which sees “"disability' as a potential site for collective reimagining" (Kafer, 2013, p. 9). Under this model, it becomes possible to recognize that impairment and disability can be an embodied experience that significantly impacts quality of life in ways that 
motivate people living with those impairments to seek treatment and cure, while simultaneously

seeing disability as a site of radical reimagining that can lead to new possible futures that view

disability as desirable. Kafer (2013) summarizes this eloquently when she states:

As much joy as I find in communities of disabled people, and as much as I value my experiences as a disabled person, I am not interested in becoming more disabled than I already am. I realize that position is itself marked by an ableist failure of imagination, but I can't deny holding it. Nor am I opposed to prenatal care and public health initiatives aimed at preventing illness and impairment, and futures in which the majority of people continue to lack access to such basic needs are not futures I want. But there is a difference between denying necessary health care, condoning dangerous working conditions, or ignoring public health concerns (thereby causing illness and impairment) and recognizing illness and disability as part of what is desirable-sketching out some of the potential differences is exactly the work we need to be doing. (p. 4, emphasis added)

Crip theory also embraces a material politics that recognizes existing oppressions and attempts to imagine disability futures that alter existing social structures of power to advance disability justice and social justice more broadly. As McRuer (2006) states: "The fact that some of us get beaten and left for dead tied to deer fences or that others of us die virtually unnoticed in underfunded and unsanitary group homes should be enough to highlight that the heterosexual/queer and able-bodied/disabled binaries produce real and material distinctions" ( $\mathrm{p}$. 157). This is also in keeping with the goals of critical disability studies more broadly, which includes a goal of producing knowledge that is not confined to academia, but rather intended to tangibly support movements to advance justice for marginalized groups (Hall, 2019).

This encourages us to consider: what does it look like to apply crip theory in praxis? In other words, what does it mean to "crip"? According to McRuer, in practice, crip theory involves: building a complex relationship with identity that claims disability while remaining critical of identity politics as a whole; claiming the process of coming out as disabled as an important political move; demanding that an accessible world is possible and imagining 
accessibility in broad ways; and insisting that a disabled world is both possible and desirable (McRuer, 2006). Margaret Price (2015) further conceptualizes crip politics as a way of getting things done, "moving minds, mountains, or maybe just moving in place (dancing)—by infusing the disruptive potential of disability into normative spaces and interactions" (p. 207). Thinking through the praxis of crip theory as it applies to chronic pain will be central to this thesis. The crip theory maxim that coming out as disabled is an important political move is also critical to the epistemology of my work, which will be explored in the next section.

\section{Reflexivity and Epistemology}

The interplay between crip theory and standpoint epistemology has shaped my work, and the lived experience of people in pain, including myself, is at the centre of that. Epistemology and crip theory converge in pain research to create a "cripistemology" of pain, which is "a process of knowledge production that situates pain within discursive systems of power and privilege. The structural conditions that underwrite the devaluation of lives with pain (and by extension disabled lives) must be exposed and critiqued" (Patsavas, 2014, p. 205). Patsavas goes on to explain that "cripistemology" merges the concept of "cripping" normative structures by challenging their dominance with standpoint epistemology, which highlights the importance of considering subject positions when producing knowledge (Patsavas, 2014). This is further expanded by Sheppard (2019) who argues that chronic pain becomes a part of the phenomenological self, which means that the knowledge produced by chronically pained people is inevitably shaped by living with pain. From Sheppard's perspective, “cripistemological knowledge about chronic pain can therefore only be produced by chronically pained people" (para. 4). Cripistemology is a valuable tool for considering chronic pain because it validates the person living with chronic pain as a legitimate producer of knowledge about their own 
experience, separate from medical diagnosis or recognition. It also allows for a reframing of pain that does not necessarily see it as life-ruining, or as something that devalues the life of the person experiencing it (Patsavas, 2014). This epistemological position is critical to hermeneutical justice, a concept I expand on in chapter two. By focusing on lived experience as a legitimate form of knowledge, it also becomes possible to reveal issues of chronic pain as gendered, classed, racialized, and otherwise mediated by social systems of power and privilege. My own subjectivity as a researcher who is queer, disabled, and white is therefore critical to reflect on when incorporating my own autoethnography.

Despite identifying as disabled and queer, none of that erases the socio-political power and privileges that are afforded to me by being white. My own experiences of navigating diagnosis and medicalization that will be explored in chapter two are mediated by white privilege, as well as class privilege and access to universal healthcare. I can navigate the world and my research without consideration for how it reflects on my entire racial or ethnic group. I can safely assume that the work I produce, even if controversial or "edgy" will not create political or social difficulties for white people, because my own personal experiences and narratives will not be assumed to apply to my entire demographic. I have the exceptional privilege of being seen as an individual who speaks for herself only. While Sheppard's (2019) argument that research about pain should be produced by chronically pained people is important, it must also be framed in a context that recognizes that the experiences of such people are still shaped and constrained by inequitable structural power relations that impact our lived-experience perspectives.

Juana María Rodríguez (2011) argues that racialized subjects are held to standards of respectability that white subjects are not under the premise that it is their role to serve the 
common good. Amber Musser further points out that ideals of respectability are based in the false belief that "discipline and assimilating to a heteronormative, monogamous ideal will foster a non-racist future" (Chude-Sokei et al., 2016, p. 51). Thus, when thinking about the privilege of whiteness, we can recognize that white subjects enjoy a certain freedom to pursue and revel in pleasures with little concern for the larger social consequences. Whiteness simultaneously creates the benchmark for what is considered respectable, while also exempting itself from having to live up to that standard. As a white researcher, I am not bound to these higher norms of respectability. I am allowed a certain degree of deviance from the norm in a way that is considered sexy, not disreputable.

I have chosen to situate myself within my research for many reasons. Individual experiences of pain are so unknowable to others that it can be uniquely challenging to universalize pain into a shared experience or shared knowledge. I am an insider in the sense that I experience chronic pain, but each experience of pain is deeply personal. No matter how similar our experiences, I will never truly understand another person's pain. I am disabled, but I typically pass as able-bodied to outsiders. I am queer, but I often pass as straight. While I struggle with the sense of invisibility this causes, I also acknowledge that there is some privilege embedded in my ability to pass unnoticed in a heteronormative, ableist world. These are some of the reasons that, as authors like Acker (2000), Bridges (2001), and Sherif (2001) point out, it is not as seemingly straightforward as insider-outsider. Most of us are made up of a range of different identities and may be perceived one way by outsiders while feeling another way in our lived and embodied experience of the world. It is thus important to challenge unmarked categories through self-identification, while simultaneously recognizing that this self- 
identification does not imply that a researcher's personal experience can necessarily be universalized to all people who share their identity category.

Crip theory engages with epistemology further when it challenges the distinctions between public and private in common understandings of knowledge production (Bahner, 2018). Challenging the public/private binary recognizes that for disabled people,${ }^{5}$ the notion of distinct public and private lives is unrealistic, as navigating the world as a disabled person often demands a level of disclosure and vulnerability not usually required of nondisabled folks. As a result, public/private binaries must be challenged to give validity to the lived experiences of disabled people. Craene (2017) argues that the disembodied approach to research that is common in academia often fails to consider the power imbalance created when we expect research participants to disclose intimate details of their lives without any willingness to be equally vulnerable about our own. Further, their own able-bodiedness is often an "unmarked category" that nondisabled feminist researchers fail to acknowledge or engage within their work (McRuer, 2010), so I also situate myself to challenge this issue. My reflexive and epistemological position is best summarized by Patsavas (2014)—with support from McRuer—who states:

Refusing that hierarchical arrangement of knowledge, I work from what Robert McRuer calls a critically queer and severely disabled position (31). McRuer contends that such positionalities materialize "precisely those bodies that are best positioned to refuse 'mere toleration' and to call out inadequacies of compulsory able-bodiedness" (31). In that sense, I propose an analytic that builds from pain - $m y$ "critical" and "severe" pain - foregrounding an experience often considered the most unincorporable disability experience. (p. 206)

\footnotetext{
${ }^{5}$ Within disability studies, there are a range of preferences in terms of person-first language (person with a disability) and identity-first language (disabled person). I identify as a disabled woman (identity-first) and will primarily reflect that language in this thesis but will note that person-first language may still appear in direct quotes and other external sources.
} 
My position as a critically queer and disabled scholar shapes my work and my epistemology, and those positions in turn inform my methodology, which will be outlined in the next section.

\section{Methodology}

I broadly frame this research as feminist ethnography but I also incorporate elements of queer theory that challenge the fixed subject position that is often central to definitions of feminist research (see Hesse-Biber, 2014; Harding, 1989). For example, Sharlene Nagy HesseBiber (2014) argues that "research is considered 'feminist' when it is grounded in the set of theoretical traditions that privilege women's issues, voices, and lived experiences" (p. 3). This is challenged by Hannah McCann (2016), who points out that "despite feminist attempts at deconstructing the binary, gender categories are often reinforced through the research process, as the gendered subject is made the object of study" (p. 229). By not limiting my research to only participants who identify as women, my intention was not to undermine the reality that people who are culturally read as feminine often face significant disparities in healthcare, and are routinely disbelieved by medical providers for reasons that can be attributed to gender or gender presentation. My research includes queer subjectivities, and queering feminist ethnography is a critical part of recognizing these subjects. I rely on three components of (queer) feminist ethnography: analysis of discussions of chronic pain and BDSM on public platforms online, including blogs, online magazines, and social media; in-depth, loosely-structured one-on-one interviews with two adults living with chronic pain who also participate in BDSM; and autoethnography. 
In early 2018, I read the personal essay "Unbound” by Lauren Kayes (2018), which discusses Kayes' experiences with chronic pain, and the unlikely source of relief they discovered for that pain:

I'm startled sometimes by the brightness of BDSM, the pain I opt into. On its surface it's awash in a dim red glow, all heavy chains and rubber ball gags, mistresses wrapped in PVC and breath-stealing corsets. That manufactured darkness is there, if you want it - and sometimes I do. But I find that I laugh during play — not a misnomer - more often than I cry, giggling when a flogger tail tickles my shoulder blade, snorting after I gasp at an unanticipated smack...My heart relishes the catharsis of the dark, but sometimes all my body needs is that bright edge to crack open the joy in pain. (para. 27)

After reading this essay, I conducted a literature review to establish what existing research was available on BDSM as a tool for reimagining physical pain, and what gaps still existed in the research. While some limited research on BDSM and chronic pain exists (Lindemann, 2014; Reynolds, 2007; Sheppard, 2018, 2019; Tellier, 2017), the majority of the writing I found on the topic existed outside academia on online platforms such as blogs, social media, and online magazines. With this in mind, I began searching for existing discussions of chronic pain and BDSM on various online platforms and analyzed them for broad themes using ethnographic content analysis. Participants whose first-person online narratives were analyzed and whose words will appear throughout this thesis include Carrie (she/her), Lauren (they/them), Sara (she/they), Amanda (she/her), Xan (they/them), Andrea (she/he/they), and S. Naomi (they/them). All of these participants identify as queer. Other demographic information such as race, class, or geographic location was difficult to discern for most of these writers. While all of the authors included pronouns in their bios, I will not make assumptions about their specific gender identities as this information was not explicitly stated.

In their handbook Qualitative Media Analysis, David L. Altheide and Christopher J. Schneider (2013) explain that ethnographic content analysis (ECA) blends the idea of objective 
content analysis with participant observation in order to understand culture, social discourse, and social change. In their conception, documents including online platforms are critical tools for understanding shifts and changes in culture and meaning (p. 5). Altheide and Schneider also argue that traditional approaches to content analysis believed "true knowledge" required numbers and measurement, and thus depended on a quantitative approach, a perspective that is challenged by the ethnographic focus of ECA. As George (2009) highlights, unlike quantitative research, under qualitative analysis the existence (or presence) of a particular idea or sentiment within the data can be treated as important, even if it occurs infrequently or only once. In highlighting the value of ethnographic content analysis, Altheide and Schneider point out that an ethnographic approach can allow researchers to use document analysis as a form of fieldwork (2013). It is also important to note the distinctions between ECA and grounded theory, although there are many similarities. While grounded theory focuses on systematic and rigorous coding of available data, ECA is focused on concept development. It is informed by the idea that "the general process of data collection, reflection, and protocol refinement is more significant for a study" than rigorous coding (Altheide and Schneider, 2013, p. 27). ECA was thus a useful tool for establishing an initial understanding of the major themes and concepts that emerged in the existing non-academic literature on BDSM and chronic pain, which then helped inform the design of the interview stage of the project.

After identifying broad themes using online first-person narratives, I chose to do two indepth interviews with people living with chronic pain who participate in BDSM to gain a deeper and more nuanced understanding of their lived experiences. I used loosely-structured one-on-one interviews to gather qualitative data, and the interviews relied primarily on questions that encouraged a narrative and self-reflective approach. Part of the value of a loosely-structured 
approach is that "careful listening allows the interviewer to introduce new questions as the interview proceeds. Thus, the interviewer, the interview, and the study become interviewee oriented" (Reinharz, 1992, p. 21). Further, this is in keeping with one of the central tenets of the disability rights movement that foregrounded disability justice organizing: "nothing about us, without us" (Charlton, 1998). Reinharz (1992) emphasizes the value of this approach, pointing out that allowing interviewees the ability to share their ideas and experiences in their own words is especially important for research on women because it challenges the historical tendency of ignoring the needs of women or having male researchers speak on behalf of women. This is equally applicable to research on other marginalized populations like disabled and sick people who have historically been silenced by researchers, parents, and medical providers. My original intention was to recruit participants the following ways: posters placed on billboards and other approved locations at Carleton University, circulating a digital copy of the recruitment poster to the administrator of the Institute of Women's and Gender Studies for distribution to their email list, sharing the poster to social media, and snowballing. Participation was limited to people who self-identified that BDSM was an active part of their life. Research participants were geographically located in Canada (although citizenship was not a factor considered in recruitment). Participants were also required to be $18+$. The first recruitment tactic I used was sharing the poster to social media, where it was quickly shared numerous times by people in my network. Within the first day of posting, I had received enough initial inquiries from interested participants that I did not need to pursue any of my other proposed recruitment techniques.

I intended for each interview to last approximately one hour. ${ }^{6}$ Each participant was only interviewed once, and interviews were audio-recorded (with informed consent). Before

\footnotetext{
${ }^{6}$ In practice, the interviews lasted between 22 minutes and 1 hour and 10 minutes.
} 
beginning each interview, the participants reviewed and signed an informed consent form and were give another opportunity to ask any questions they had about the study. Participants were asked about demographic information at the beginning of the interview. The interviews took place either in person on the Carleton University campus, or over Skype if distance or other access concerns prevented in-person interviews. American Sign Language (ASL) interpretation was offered as an option to any participants who required it but was not requested by any participant. $^{7}$

I recruited two adult participants for the in-depth interviews. Both participants will be identified by pseudonyms throughout this thesis: Ruby (she/her) and Sam (she/her/they/them). Participants were located in Canada (Ontario and Saskatchewan), and ranged in age from 34-42. Chronic pain is defined in most medical literature as pain that lasts longer than 3-6 months (Treede R. D. et al, 2015). For the purposes of this study, I used the upper end of that scale and defined chronic pain as pain that persists for a duration of 6 months or longer. ${ }^{8}$ The participants had lived with chronic pain for significantly longer than the minimum cut-off of 6 months, with both estimating that they had been living with chronic pain for approximately 20 years.

While both participants noted that they could trace some interest in BDSM back to their teenage years, they stated that it had been a more significant part of their lives for 4-7 years. Both participants identified as queer. One participant identified as female, and another identified as trans/gender nonconforming (specifically demi-femme). One participant identified as white, and

\footnotetext{
${ }^{7}$ I transcribed the audio recordings from the completed interviews. The transcripts were de-identified by removing all names or other identifying information such as place of work. Once the transcripts were cross-referenced for accuracy and de-identified, the original audio files were destroyed. The transcripts were analyzed using an informal manual coding process that looked for particular themes and concepts that emerged in participants' own words. The themes that emerged then informed the creation of a theoretical understanding of BDSM as a mechanism for reimagining relationships with pain.

${ }^{8}$ This was less to align with medical/diagnostic frameworks, and more to ensure participants had lived with chronic pain long enough that they would likely have a lot to discuss in their interviews.
} 
another identified as Métis. Although relationship status was not factored into recruitment for this study, both participants identified as polyamorous. ${ }^{9}$

Roger and Mignone (2018) argue that the purpose of ethics protocols should always be focused on getting a more thorough understanding of how our participants' vulnerability might position them with regards to the research, and us as researchers. My research focuses on people who predominantly identify as sick and/or disabled, and all identify with queerness and sexual sub-cultures. Many have dealt with histories of pathologization and medical scrutiny and may have sensitivities to the idea of being observed or studied. Disabled populations and BDSM practitioners are accustomed to the outside world demanding to know why they are the way they are. This feeling can easily be reinforced by well-intentioned but careless research practices. This study went through a full approval process with the Carleton University Research Ethics Board (CUREB) A. This process required stringent confidentiality policies, debriefing and access to support for participants, and a comprehensive consent process that explained all possible risks to participants and the steps taken to minimize potential harm. The study was carried out in strict adherence to these policies.

The final method I incorporated into my work was autoethnography. As highlighted earlier in the introduction, research on chronic pain is most useful when it is undertaken by people who live with chronic pain themselves. It was therefore important to situate myself not only from a reflexive standpoint, but also to highlight the ways that I can relate to the experiences of invisibility and hermeneutical injustice that emerged in the analysis and contribute my own experience to the theorization of chronic pain. As Bochner (2011) explains:

Autoethnography is an approach to research and writing that seeks to describe and systematically analyze personal experience in order to understand cultural experience. This approach challenges canonical ways of doing research and

\footnotetext{
${ }^{9}$ This was also true for many of the authors of the first-person online narratives I analyzed.
} 
representing others and treats research as a political, socially-just and sociallyconscious act. (p. 273)

It also recognizes the "impossibility of and lack of desire for master, universal narratives" (p. 274). My autoethnographic experiences with chronic pain and medical diagnosis will provide context for chapter two, but first I will provide a brief overview of central themes, a summary of the remaining chapters and an overview of key BDSM terminology.

Crip theory provides a framework for thinking of disability ${ }^{10}$ differently, resisting compulsory able-bodiedness in distinctly anti-capitalist ways. Many of these imagined disability futures are rooted in interdependence and desiring disability. It is through this framework that we can consider two of Patsavas' questions:

- First, "how differently [might we feel] pain in a context where interdependence is acknowledged and valued?” (Patsavas, 2014, p. 209)

- Second, what strategies can we use that "permit us to think pain otherwise, to produce painful new knowledge, but also to construct analyses about pain that are less painful, and less dangerous to those of us in pain, and, in doing so, to reimagine our (shared, pained) futures"? (Patsavas, 2014, p. 216)

In the following chapters, I will argue that one space that allows people with chronic pain to explore these questions is the $\mathrm{BDSM}^{11}$ scene. BDSM merges together three different acronyms: B\&D, which stands for bondage and discipline; D/s, which stands for Dominance and

\footnotetext{
${ }^{10}$ For the purposes of this research, chronic pain is considered disability, although not all people with chronic pain identify as disabled, and not all disabled people are in pain.

${ }^{11}$ While BDSM is non-normative, it is not necessarily inherently radical in its own right, but rather can become radical practiced in particular ways. Bauer (2014) argues that at its best, BDSM can be about "pushing one's limits and changing one's relationship to the boundaries one engages with, ultimately leading to a transformation of the self, to processes of resubjectification" (p. 163). It is this vision of BDSM that can be radical and transformative, and this understanding of BDSM that will be explored here.
} 
submission; and SM, which stands for sadomasochism (or sadism and masochism) (Weiss, 2011). It is also important to note that the capitalization of Dominance paired with the lowercase submission is a stylistic convention within the BDSM community, and not an error. BDSM may also be used interchangeably with the word kink (or kinky), although kink arguably encompasses a broader range of practices than BDSM. For the purposes of this research, the terms will be used interchangeably nonetheless, as the terms were often used that way in the data collected. While BDSM can involve inflicting or receiving physical pain, pain is not a necessary component of all BDSM practices (Weiss, 2011). For many, BDSM is about power and control, which may or may not involve playing with pain. Within BDSM practice, participants may refer to their interactions as play, or as a scene. This should not be confused with the scene, which is another term sometimes used to refer to the BDSM/kink community at large (Weiss, 2011). Within BDSM there are numerous commonly used titles and roles. A person may identify as Dominant, which may also be called a Top. Commonly used titles for Dominants or Tops include Master, Mistress, Sir, Daddy, Mommy, Lady, Dom, or Domme, although this is not a comprehensive list. A person may also identify as a submissive or a bottom. The titles used for submissives vary widely and are often quite personal. Some people also identify as a switch, which refers to someone who is comfortable in either a Dominant or submissive role (Weiss, 2011). A sadist is a person who enjoys inflicting pain on others, and a masochist is a person who enjoys receiving pain. Dominants may be, but are not always sadists, and submissives may be, but are not always masochists. There are a range of sub-categories under the umbrella of Dominant, submissive, sadist, and masochist (Weiss, 2011). Finally, "vanilla" refers to either a person who does not identify as kinky, or sexual practices that are not considered kinky (Weiss, 2011). 
As a space where pain is welcomed in all its complexity and allowed to be fully experienced, BDSM allows participants to think of pain differently and relate to it differently. It does not demand a particular response, but rather gives space for exploration. It challenges the hermeneutical injustice of chronic pain by allowing people who live with pain to express it, share it with others, and be fully seen in pain, while also encouraging interdependence. It is through this process that it becomes a small example of queer utopia as Muñoz imagines it - a space of potentiality where different futures and different perspectives on pain can be imagined and explored.

To explore this further, the remainder of this thesis will be divided into two sections. Chapter two will set the context by connecting autoethnography to current literature on chronic pain-especially chronic pain in the context of critical disability studies; current debates in the field about diagnosis, treatment and cure; and the hermeneutical injustice and violence of chronic pain. Chapter three will include an analysis of major themes that emerged in my data and connect them to theories of queer utopia and crip/queer futurity, making the argument that BDSM in its more radical forms can be a space of collective reimagining and world-making.

My overall aim is to contribute to the theorization of hermeneutical justice by considering the embodied experience of BDSM and pain and the way that this can be a productive site of resistance to compulsory able-bodiedness. I also hope to contribute to crip theory by addressing the critique that the crip theory maxim of desiring disability fails to deal with the "realities" of disabled bodies, including physical pain. I hope to provide a framework for a different understanding of pain that both recognizes the challenges pain can present, while also acknowledging that the unique ways some people with chronic pain seek out pleasure and connection can be a generative disruption of non-disabled social relations. I am also sympathetic 
to Bannerji (1995), who argues that it is not enough to simply write about alternate visions for the world. She states: "we have to end the oppressive conditions, the social organizations, ultimately not of our own making, which give rise to our experience" (p. 82). This leads me to question how my research can be used to create tangible change. I argue that in an ableist world that views disabled lives as less worthy of living, research that reframes pain or disability in ways that are life-affirming and even rooted in pleasure challenges larger systems of oppression and power that create barriers for disabled people. These challenges are a critical step towards social change and are transformational on the ground. 


\section{Chapter Two: The Complexities of Pain, Invisibility and Diagnosis}

\section{A Brief Autobiography of Chronic Pain}

I was around 15 the last time I experienced a day without chronic pain, but I did not know it was the last time then. Throughout my childhood, there were always little hints that something was wrong. When rainy weather approached, my joints would ache and throb. I would often wake up crying in the night from seizing muscles in my calves and feet. "Growing pains," the doctor said. I was clumsy and accident-prone, but like the growing pains, this was attributed to my tall, lanky frame. By the time I was a teenager, I had experienced multiple sprains, a handful of broken bones, torn ligaments, and was routinely covered in bruises. The pain in my joints was becoming more persistent, and at 13 I was finally referred to a specialist who told me that flat feet were responsible for all of my nagging symptoms. I was referred to physiotherapy and fit for custom orthotics, and I was assured that would solve the problem. It did not.

As my teens progressed, the pain got worse. It wasn't just my joints anymore. A friend gently poked me in the arm to get my attention, and I nearly cried from the pain. I started having problems with my digestion. My period would announce itself each month with pain so severe I would vomit and black out on the bathroom floor. I was prescribed birth control to manage my periods, and told the digestive problems were irritable bowel syndrome or lactose intolerance. After years of inconclusive tests, I stopped mentioning the pain, beginning to believe the doctors who suggested I just had a low pain tolerance.

By the time I was in university, chronic, unrelenting pain had become my new normal. Every time I thought I had surely reached the plateau, that my body couldn't decline any further, something new would arise. I started having trouble breathing and was referred to a pulmonary 
specialist. He performed pulmonary function tests and told me my oxygen diffusion rate was extremely low, and my circulation was poor. He ordered a chest x-ray, and then sat me down. "Based on what we can see in your X-ray, it looks like pulmonary fibrosis, but I'll need to do more tests to confirm. In the meantime, stay off of Google."

I Googled it as soon as I got home. Reading WebMD, I started shaking as I read the words "average life expectancy from time of diagnosis is three years." I was 21 . In a moment of overwhelming terror and anger, I picked up the glass sitting next to me on my desk and smashed it against my bedroom wall. My partner, who I had been dating for only three months, ran upstairs and found me sobbing on the floor next to the broken glass. I told him that the doctor thought I might be dying, and we cried together on the floor.

I got another call from the specialist. He had scheduled me for follow-up testing, a highcontrast CT scan of my chest, but the wait time was six weeks. For six weeks in my fourth year of undergrad, I lived in limbo, not knowing if I was terminally ill or not. The weeks crawled by, but the time finally came for my CT scan. After the test, I waited for the pulmonary specialist to review the results. When he finally came in, he cheerfully quipped "Good news! We were wrong. It's not pulmonary fibrosis. Your lungs look fine.” He seemed puzzled by my sudden tears. "You Googled it, didn't you?" he asked. When I didn't respond, he went on to tell me that although my lungs looked fine, my low oxygen diffusion rate was still indicative that something was wrong, but he was at a loss for what it could mean. He recommended I see a cardiologist.

That began a multi-year process of confused specialists. The cardiologist identified a heart murmur, but said it seemed to be benign. Brain MRIs and neurological exams were normal. Nerve conduction studies and electromyography suggested overactive nervous system activity, 
but no explanation for why. Blood tests came back normal, but ultrasounds of my thyroid showed a multinodular goitre. X-rays of my joints were consistent with arthritis, but I tested negative for blood factors for rheumatoid arthritis, the only form of arthritis that made sense for a woman in her early 20s. Despite the negative blood tests, the specialists gave me a diagnosis of seronegative rheumatoid arthritis and fibromyalgia, stating outright that they did not think the diagnosis really fit, but also that they were running out of ideas for what else it could be. The heavy drugs they prescribed-including an experimental drug in the same family as the chemotherapy drug methotrexate-made me worse, flaring my pain and causing serious mental health-related side effects, including hallucinations and psychosis. They aggravated my digestive symptoms and worsened my circulation. When I complained of severe side effects to my medical team, they told me that what I was describing were not known side effects of the drug, and that I must be either exaggerating the effects or mistakenly ascribing them to the medication. They initially refused to wean me off the drug, until I threatened to stop cold turkey and asked that they note their refusal to wean me off safely on my medical chart. I later learned that the reason the drug was classed as "experimental" was because it had never been tested on women.

My family doctor suspected that the rheumatoid arthritis diagnosis was wrong and referred me to a different rheumatologist for the suspected fibromyalgia instead. In a letter from that rheumatologist dated June 14th, 2011, he agreed with fibromyalgia as a diagnosis, and wrote: "Her treatment options include Lyrica, Cymbalta, ${ }^{12}$ and then a referral to a clinical psychologist to learn other tricks to control her pain, if she can afford that. I have also encouraged a regular exercise program.” This would be the first of many suggestions that

\footnotetext{
${ }^{12}$ Lyrica is the brand name for pregabalin, an anticonvulsant. Cymbalta is the brand name for duloxetine, an antidepressant.
} 
antidepressants and an attitude and lifestyle shift would be adequate to manage my pain, but not the last. In March of 2016, another doctor performed a Chronic Pain Coping Inventory (CPCI) on me. When I got the report back, it stated: "Relative to the CPCI standardization sample, Ms. Jobson's Coping Self-Statements Scale falls within the clinical range...Such scores likely suggest the need for improvement in the coping response assessed by this scale. Based on the findings, Ms. Jobson might benefit from coping skills training and encouragement to increase purposefully thinking positive thoughts about the pain problem."

Despite my best efforts to "purposefully think positive thoughts," as my 20s progressed, my pain got worse. I gave up on the idea that I would ever find an explanation for my lengthy list of symptoms. I started to believe the specialists who had hinted or outright stated that I was a hypochondriac, or that I was just clinically depressed. ${ }^{13}$ When I was 30, I visited a physiotherapist for a shoulder injury. On my first visit, she asked for my medical history. "All of it?" I asked. "All of it," she nodded. We spent the entire appointment talking about the last decade of my life. She took detailed notes, and I saw her scribbling comments in the margins and drawing arrows between things I said. At my next appointment, she asked me to change into shorts and a t-shirt. Looking at me with a furrowed brow, she asked: "Do you always bruise like that?" My legs were covered in dark, mottled bruises. "Yes," I said. "I've always bruised like a peach." She started making strange requests. She asked me to stand up and put my hands on the floor, noting that I could put them flat on the floor with minimal effort. She asked me to bend my thumbs toward my wrists and noted that they touched. She bent my fingers backwards and had me extend my knees and elbows as far as they could go. When she was done, she said "did any

\footnotetext{
${ }^{13}$ I do not use "just" here to trivialize the experience of clinical depression, but rather to highlight that this is how it was typically framed by doctors at this time. "Just depression" was the go-to response from many of the medical providers I saw who could not think of any other explanations for my symptoms but felt the need to label it.
} 
of the specialists you saw over the last 10 years ever raise the possibility that you have EhlersDanlos Syndrome?" They had not. I had never heard of it. "It's rare, but I see another patient who has it. Your symptoms and medical history are almost identical to hers."

I went home and Googled Ehlers-Danlos Syndrome (EDS). As I read about it, I was overcome with deep, heavy sobs. The sobs did not signal feelings of devastation this time, but of relief. My pain and other bodily experiences were not the result of depression nor bad attitudes. Neatly organized into a diagnostic chart in front of me was every strange and apparently unrelated symptom I had ever experienced. I was textbook. My medical history fit neatly into the diagnostic criteria. A genetic connective tissue disease, EDS causes the body to create faulty collagen, resulting in hypermobility, lax joints, an unreliable cardiovascular system, and poor digestion. Untreated, this syndrome manifested itself with widespread chronic pain, susceptibility to injuries, easy bruising, and baffling and seemingly unrelated symptoms in almost all parts of my body.

I was referred to a geneticist to confirm the suspected diagnosis. The wait for an appointment with the only EDS specialist in this region of Ontario was almost 2 years. When my appointment came, I spent three hours with the geneticist and her resident. They later told me that they knew I had connective tissue disease the moment I walked in the office door. It was "unmistakable." 14 After ten years of misdiagnoses, worsening pain, and specialists denying the

\footnotetext{
${ }^{14}$ Like many people with connective tissue disease, I have many of the features of "marfanoid habitus," a specific collection of bodily features. In my case this includes large, prominent eyes; a narrow palate; a prominent rib cage; very long fingers paired with very thin wrists; long, narrow feet, and unusually soft skin. This makes my otherwise invisible illness "visible" to the select few specialists who are well-acquainted with genetic connective tissue disorders, and therefore "unmistakable."
} 
truths about my own experience of living in my body, my connective tissue disease was "unmistakable."

I still live with chronic pain. EDS is not curable, and the decades I spent undiagnosed caused a host of irreversible damage. My joints have been severely compromised, and I may require hip replacement surgery on my right hip in the not-too-distant future. My neck is so unstable that I was referred to a neurosurgeon to evaluate whether or not I was a good candidate for spinal fusion surgery (the insertion of metal rods alongside my spine to stabilize it). We have decided to wait for now, as the surgery comes with significant risks. Some days are better than others. Some days I walk easily (although never without pain), others I can barely get myself out of bed, and certainly can't climb stairs or walk long distances. The vertebrae in my spine are mostly eroded, as is the cartilage in most of my major joints. My fingers and kneecaps dislocate at random. I often wear braces or kinesiology tape on my ankles, knees, wrists, and fingers to help with balance. I wear compression clothing to help with blood circulation (without them I am prone to fainting) and attend physiotherapy weekly to strengthen my muscles and help them stand in for my weak ligaments and tendons. I have never forgotten what it felt like to feel that invisible, and to be told repeatedly that my own lived experience of what I was feeling in my body wasn't real because it wasn't measurable with standard medical tests.

For most of the ten years I spent seeking a diagnosis, I was in survival mode. Finding a diagnosis felt like the golden ticket that would prove not only that what I was experiencing was real, but also that I was not a failure. My fatigue, brain fog, and pain made it impossible for me to keep up with straight capitalist time without serious consequences, but those same systems demanded answers and accountability if I fell behind. All of my limited energy was committed to faking being well. In my demanding job, I routinely worked 16-hour days, entirely on my feet, 
often in heels. Working for a national organization, I was flying all over the country, taking up to 20 flights a month even though flying made my pain flare more than anything else. I refused to stop, no matter how much my body warned me that continuing to ignore it was unsustainable. Then, abruptly, everything stopped against my will. I had recently started a new job. Standing at the bus stop in the early morning on my way to work, my body was suddenly flooded with intense pain that I could no longer ignore. My brain responded to the pain with adrenaline, and as my heart rate escalated, I had a severe panic attack on the side of the road. I managed to text my partner who picked me up and took me straight to my doctor. After injecting muscle relaxants into my back and making me drink a cup of Pedialyte, she printed out a note: "To whom it may concern: This patient was totally disabled on Friday, December 9, 2016. Estimated time until return to work: unknown." It was the day after my $30^{\text {th }}$ birthday. I didn't return to work at all for 6 months, and never returned full-time.

In my sudden and unplanned slow-down, I could no longer run away from my pain. It was shortly after this that I finally received my diagnosis, but instead of giving me a cure, what diagnosis gave me was permission to be sick. I found myself living in crip time while the world around me marched on and pain became an integral and unavoidable part of my daily life. Describing crip time, Ellen Samuels (2017) states:

It requires us to break in our bodies and minds to new rhythms, new patterns of thinking and feeling and moving through the world. It forces us to take breaks, even when we don't want to, even when we want to keep going, to move ahead. It insists that we listen to our bodyminds so closely, so attentively, in a culture that tells us to divide the two and push the body away from us while also pushing it beyond its limits. Crip time means listening to the broken languages of our bodies, translating them, honoring their words. (para. 11)

As I learned to sit with pain, searching and finding moments of pleasure alongside it felt even more valuable and radical. Sex and sexuality fascinated me. I used my newfound free time to 
read a lot of books on these subjects. As I read more about BDSM, I was intrigued by how pain was centred, instead of hidden. In this context, giving in to pain was an alternative to running from it or attempting to overcome it. It also provided a framework for thinking of pain as something that could be shared, instead of something inherently isolating. Until I was forced to stop, I could only understand pain as something I had to overcome if I wanted to live a fulfilling and meaningful life. Suddenly I was being presented with an alternative perspective, one that welcomed pain and saw potential for connection and intimacy alongside it. Abruptly removed from the capitalist workforce and dependent on the support of others, I started to see the "failure" of my body that I had tried to avoid for so long as inextricably linked to the messages I had absorbed over time that tied my value to my productivity and independence. As I gave myself space to engage with pain, the structural and social conditions that had motivated me to hide it for so long became increasingly apparent. I began to think of my pain not as an isolating or solitary experience that I had to overcome to prove my independence, but instead as a reminder that there is value to slowing down and shifting towards interdependence. This was a radical ideological shift, and a move away from more conventional understandings of pain as isolating and unsharable. These existing theories of pain will be explored in the next section.

\section{Theories of Pain}

Physical pain happens, of course, not several miles below our feet or many miles above our heads but within the bodies of persons who inhabit the world through which we each day make our way, and who may at any moment be separated from us by only a space of several inches. The very temptation to invoke analogies to remote cosmologies (and there is a long tradition of such analogies) is itself a sign of pain's triumph, for it achieves its aversiveness in part by bringing about, even within the radius of several feet, this absolute split between one's sense of one's own reality and the reality of other persons. Thus when one speaks about "one's own physical pain" and about "another person's physical pain," one might almost appear to be speaking about two wholly distinct orders of events. For the person whose pain it is, it is "effortlessly" grasped (that is, even 
with the most heroic effort it cannot not be grasped); while for the person outside the sufferer's body, what is "effortless" is not grasping it (it is easy to remain wholly unaware of its existence; even with effort, one may remain in doubt about its existence or may retain the astonishing freedom of denying its existence; and, finally, if with the best effort of sustained attention one successfully apprehends it, the aversiveness of the "it" one apprehends will only be a shadowy fraction of the actual "it"). So, for the person in pain, so incontestably and unnegotiably present is it that "having pain" may come to be thought of as the most vibrant example of what it is to "have certainty," while for the other person it is so elusive that "hearing about pain" may exist as the primary model of what it is "to have doubt." Thus pain comes unsharably into our midst as at once that which cannot be denied and that which cannot be confirmed. (Scarry, 1985, p. 4)

In Elaine Scarry's genre-defining work, The Body in Pain, she argues that one of the central problems of pain is that it is simultaneously undeniable to the person experiencing it, and doubtful to outside observers (Scarry, 1985). Scarry further argues that pain is an experience that is dehumanizing and analogous with death. The idea of pain as metaphorical death fuels the idea that lives lived in pain are not worth living by suggesting that a life in pain is already as good as being dead. Another part of what Scarry is arguing is that pain intensifies the border between self and other. It is this understanding of pain that contributes to the idea that pain is an inherently isolating experience that is thus dehumanizing, abject, and incompatible with a social and interrelational life. Other theorists have challenged the idea that pain creates an impenetrable border, however. As Patsavas argues, when pain feels unsharable to the person living with it, this is less a reflection of the actual expressibility of that pain so much as a refusal of others to recognize it (2014). In other words, the inexpressibility of pain is less a by-product of pain itself and more an outcome of ableism and social norms that frame pain as a failure of the body, a weakness of the mind, or an over-exaggeration generated for attention. She further argues that recognizing the isolation of pain as a social and structural issue rather than an inherent failure of the body is politically useful: 
Highlighting the discursive processes of isolation paves the way for recognizing pain as an experience that exceeds the boundaries of individual bodies. Working from the tradition within disability studies that values interdependence over independence and seeks to situate experiences within frameworks of relationality, I argue for a queercrip understanding of pain as a fluid, relational, and - to borrow Margrit Shildrick's understanding of leaky bodies-leaky experience that flows through, across, and between always-already connected bodies. (Patsavas, 2014, p. 213)

As Patsavas highlights, relationality and interdependence are central concepts in a lot of feminist and disability studies scholarship, and in order to engage with pain in a meaningful way, the idea of pain as individual and isolating must be challenged within this framework. By thinking of pain in the context of relationships, "the fixed distinction between pained and non-pained bodies begins to dissolve just enough to undermine discourses that individualize pain and reframe it as shareable and as shared" (Patsavas, 2014, p. 215). Sara Ahmed (2002) also takes up the issue of borders in her theories of pain. She argues that Judith Butler's concept of materialization-with its focus on the effect of surface, boundary, and fixity - can be understood in relation to the intensification of pain sensations. Ahmed points out that our awareness of our body as a material object with borders and surfaces is often forgotten while we focus on other things and navigate daily life, but pain disrupts this process. Pain "seizes [you] back to [your] body" (Ahmed, 2002, p. 21). Pain therefore makes surfaces and boundaries apparent, but she also argues that "what 'makes' those borders also unmakes them" (Ahmed, 2002, pp. 19-20). Ahmed argues that pain draws attention to the surfaces that can simultaneously separate us and connect us to others, and that when pain comes to the surface it is in relationship to others who witness or authenticate it. She further argues that her point is not to universalize the lived experience of pain or suggest that pain creates a homogenized group of people bound together by pain. Instead, she states that what she advocates for is an ethics of responding to pain that is not bound up in our ability to understand it or empathize with it: "I want to suggest here...that an ethics of responding to pain 
involves being open to being affected by that which one cannot know or feel. Such an ethics is, in this sense, bound up with the sociality or the 'contingent attachment' of pain itself' (Ahmed, 2002, pp. 23-24). Understanding Ahmed's ethical suggestion here is important, as even within critical disability studies, there is an impulse to attempt to make meaning of pain in a universal way, and this is often justified on the grounds that this is necessary to create a unified political movement around disability justice. Countering this, Ahmed states: "A political model of pain cannot gather together all the different pain experiences (this is partly my point)" (Ahmed, 2002, p. 25).

The problem of pain in critical disability studies has led to many attempts to theorize pain in politically useful ways. Siebers (2001) has argued that "the greatest stake in disability studies at the present moment is to find ways to represent pain and to resist current models that blunt the political effectiveness of these representations" (pp. 743-744). He further argues that there are a limited number of understandings of pain that are considered acceptable in the field, and that none of those are realistic for people who live with chronic pain (Siebers, 2001). However, despite Siebers' own resistance to the limited representations of pain, he does not hesitate to contribute his own clearly demarcated understanding of what pain means to people who live with it:

Physical pain is highly individualistic, unpredictable, and raw as reality...Pain is not a friend to humanity. It is not a secret resource for political change. It is not a well of delight for the individual. Theories that encourage these interpretations are not only unrealistic about pain; they contribute to an ideology of ability that marginalizes people with disabilities and makes their stories of suffering and victimization both politically impotent and difficult to believe. (Siebers, 2001, p. 746)

Siebers is arguing that it is unrealistic and damaging to frame pain as transformative or to attempt to find any positives about the experience of pain. While I agree that it is unhelpful to 
claim that pain is always transformative or life-affirming, it is equally unhelpful to claim that it never is. Attempting to do so erases the lived experiences of people who experience pain that way. ${ }^{15}$ Further, referring to pain as not a friend to humanity can reinforce narratives that dehumanize people living with chronic pain. It is important to recognize that pain can be a form of real and tangible suffering, but it is also important to recognize that it can be imagined other ways alongside that suffering, and that the social forces that conceive of lives in pain as less worth living are worth challenging. Unlike Siebers, I do not believe that thinking of pain differently is synonymous with depoliticizing disability justice.

One of the main gaps in Siebers' thinking is a misreading of the experience of pain. Pain can be experienced as both an embodied and affective phenomenon. We can create space for a range of lived experiences with pain from being agonizing to transformative while still uniting around the idea that people in chronic pain have a right to pleasure, connection, and community. When pain has a quotidian character, like chronic pain, it is entirely possible to experience it differently on a daily basis so that one could potentially feel anguish, hope, or even see it as a source of strength throughout the passage of time. Some days I am grateful for my experiences with chronic pain, seeing it as a gateway to stronger, more meaningful relationships and new ways of understanding my body and connecting with it. Other days I am in the fetal position in bed overcome with rage and despair and frustration with my body for being in so much pain. The majority of my days are spent somewhere between these extremes, in a headspace that looks more like a neutral relationship with pain. What I want to emphasize, however, is that all of these experiences of pain are valid. None are more progressive, critical, or transformative than others.

\footnotetext{
${ }^{15}$ Narratives from some people who experience pain in this manner will be explored in chapter three.
} 
When creating theories of pain, we can also argue for embracing the messiness of pain, the way it escapes a tidy definition or a universal meaning. Regardless of the embodied or affective relationship to pain an individual has, it is still possible to unite in opposition to compulsory able-bodiedness and advocate for a world that imagines disability differently. We do not advance disability justice by creating benchmarks for inclusion in the movement that require a disavowal of certain lived experiences that are inconvenient for disability theory. In other words, we can acknowledge different experiences of suffering, while also acknowledging that suffering is not justification for considering certain lives less worth living. As Fritsch (2016b) argues:

A politics of suffering is one way to bridge queer and crip theory to highlight the differential ways in which not all disabled people suffer equally, thus exposing the structural forces at play in the capacitation and withering of disabled bodies... There is no one way to experience suffering, nor can we reduce or trivialize particular instances of suffering. Although it is not possible to entirely escape the frame in which disability-related suffering has been historically shaped and mobilized to render lives as not worth living, shared social experiences of suffering can push us to think more critically about the ways in which suffering is mobilized and to whose benefit. (p. 23-24)

Arguing in favour of embracing diverse embodied experiences of chronic pain is not an attempt to ignore the realities of suffering or the complex ways social structures impact different bodies in different ways. The purpose of embracing the complexity and messiness of pain is to acknowledge that the physical experience of pain is intimately tied up in the social experience of pain. By that I mean that there are material differences in how different people living with pain are treated, and that these material differences need to be considered as part of any movement towards justice. The role of social relations in rendering lives lived in pain less worth living will be explored in the next section. 


\section{Hermeneutical Injustice}

As previously mentioned, theorists like Scarry have argued that the fundamental problem of chronic pain is its unsharability, which can lead to a sense of disbelief or invisibility. Patsavas expanded on Scarry's theory by arguing that it is not that pain is fundamentally unsharable, but that society is structurally set up to ignore and erase pain. This leads to disbelief among those who are not experiencing pain first-hand and can result in stigma, shame, and a sense of failure for those who live with pain, as Patsavas (2014) eloquently states:

Doctors would often express their mystification and frustration by telling me that there was nothing wrong with me. Their dismissal, in turn, translated into feelings of intense personal failure: I need to be punished, for all the pain I can't control. I'm ashamed of that. I'm ashamed of not being able to handle the pain. I'm ashamed of the pain I cause so many people because of it. For that I deserve to hurt. I internalized the shame and responsibility for my inability to get rid of the pain, and for the pain that I assumed I caused to others. Rereading these entries, I see not only how deeply I felt a sense of failure but also how clear it is that we never experience pain in isolation. How differently might $I$ have felt the pain in a context where interdependence is acknowledged and valued? (p. 209)

This idea of interdependence highlights that while the embodied experience of pain is a very real problem for many people with chronic pain, an additional layer that adds to the impact of chronic pain is the way pain presents a challenge to compulsory able-bodiedness and the ways that independence is framed as a benchmark for human value and worth. This mindset was central to my own experience of working to the point of literal collapse because I could not imagine a future for myself that did not centre around productivity and independence. Disabled people deal with dehumanization regularly and attempts to erase or discredit their experiences and their lives.

As Patsavas (2014) states, we

call into question the quality of a life lived in pain and paint a picture of the person experiencing pain as a creature reduced to less than human status. This cultural devaluation of life with a disability (and life with pain) has been 
pointedly categorized by Rosemarie Garland-Thomson as 'the cultural logic of euthanasia'. (p. 208)

Further, for many people living with pain, the experience of having pain is a significant part of their identity and how they experience the world (Pamich, 2006). I propose that the unsharability of pain thus becomes a form of what Miranda Fricker (2007) has labelled hermeneutical injustice, which is defined as "the injustice of having some significant area of one's social experience obscured from collective understanding owing to hermeneutical marginalization" ( $\mathrm{p}$. 159).

People with chronic pain often have their pain denied or diminished by doctors. This hermeneutical injustice in medical care for people with chronic pain was a recurring theme in both the interviews and the first-person online accounts I analyzed. For example, in describing the process of seeking medical care, Ruby stated:

I think people heard me say that I was in pain but it was almost dismissed because I was so young. But then when I went in I was like, "I can't sleep through the night anymore. My partner can't make love to me the way that we used to because I can't open my legs properly. Can you fucking please do something?"

Sam highlighted that they started noticing signs that something was wrong around the age of 14 , and first sought medical care for those symptoms at the age of 19. Despite their efforts to get a diagnosis, their pain was frequently ignored or brushed off by doctors, resulting in them not receiving a proper diagnosis until the age of 32 , eighteen years after the onset of symptoms and thirteen years after starting the process of getting diagnosed:

It took a long heckin' time to get a diagnosis...I'd talk to a doctor, they'd say "ah, all your tests are fine." Occasionally I'd get pushy with it and I finally found a good doctor who actually like...listened to my concerns and referred me to a neurologist several times and eventually a rheumatologist. 
When I asked Sam if they struggled with the invisibility of chronic pain, their response was an emphatic "YES".

In the online first-person narratives, Lauren drew connections between the ways their pain and their sexual orientation were erased under larger social norms:

None of my doctors acknowledged that my pain was unusual. They always asked if I was eating, if I was getting enough sleep, if I could be pregnant. The fainting spells were anxiety, the vaginal issues were whatever. A decade passed before I understood that black-outs and bone-deep fatigue, tremors and muscle weakness, are not typical of panic attacks; searing pain with tampon or finger insertion is also not normal. My family doctor furrowed her brow as I sobbed my way through a routine pap, even when she switched to her smallest speculum. Her solution was to only subject me to a pelvic exam every other year, so long as I was not sexually active. I didn't tell her I had sex with women, because I was always told that the kind of sex I have doesn't count as sex at all. (Kayes, 2018, para. 7)

Andrea highlights their own experience of trying to access medical care:

I have fought many a doctor who said 'your pain isn't real' or its equivalent.

'I'm sure you'll feel better soon, just rest some more.' (This, when I was barely able to leave the couch.)

'How are your stress levels? You might need to deal with your anxiety.' (I don't have anxiety. Anxiety is a real mental illness which merits treatment, not a handy excuse not to take someone seriously.)

My all-time favourite: 'You might just need to learn to cope with this.' ACTUALLY, YOU MIGHT NEED TO GET ME INTO A PAIN CLINIC OR I MIGHT LITERALLY DIE, YOU SMARMY PIECE OF SHIT. (I fired that doctor). (Zanin, 2018, para. 8)

Outside of the medical establishment, Amanda talked about how people with pain are expected to cope with their pain in ways that protect the people around them from having bad feelings about that pain:

One of the most important qualities for a successful disabled person is the ability to bear pain quietly; and not only should you bear pain quietly, but you should bear pain quietly, quietly. The most perfect disabled person receives emotional 
and physical discomfort and pain with a complete poker face, and this is in the service of a goal: appearing to experience the same amount of pain as nondisabled people, and for the same reasons. Which is to say that the most perfect disabled person appears non-disabled and is not admired by anyone for her stoicism because, if she's doing it right, no one knows she has anything to be stoic about. If you're disabled, you deserve to have pain as an invisible constant force in your life, and you deserve it so much it's not even worth mentioning. (Vivian, 2011, para. 12)

Xan expressed a similar sentiment:

I know pain. I have spent most of my life moving with pain as part of my reality. Breathing through it, moving through it, thinking through it... when possible. Passing as if I was not in pain, or not in as much pain as I actually was. And I'm very good at it. Most of the time, to most people, you would not know. If you know me real well, you might guess...I spend a good portion of my spoons ${ }^{16}$ on passing, not showing that pain to people. I learned that early, have had enough bullies in my life to know that showing pain makes the bullying worse, invites more pain, and creates a level of vulnerability that I find intolerable. Those lessons are so ingrained, so deep, that much of my effort to mask the pain I am in is not conscious, or chosen, and would be very difficult to change. (West, 2012, para. 1)

These experiences demonstrate another form of injustice that is highlighted by Emma Madden (2019). In addition to managing their own pain, many people with chronic pain need to manage other people's responses to their pain. Carrie (2014)—who has cerebral palsy—highlights another version of this that can occur for people with chronic pain who also have a visible disability:

As a way to get a grasp on the whole CP situation, people like to ask me, 'does it hurt?' In pain/not in pain is a good/bad binary that they can digest. It allows them to categorize my body in a way that makes sense, and tells them whether they should feel bad for me or not. I always say no because I don't want to give anyone (more) reason to look down on my body. But let's be real - there are screws in my spine. Of course it hurts. There's at least an unpleasant twinge happening somewhere all the time. (para. 12)

\footnotetext{
${ }^{16}$ The Spoon Theory was coined by Christine Miserandino in a blog post on butyoudontlooksick.com (now archived) in 2003. It is still a widely used analogy for explaining fatigue and other symptoms of chronic illness to nondisabled people. As a result, many chronically ill and disabled people use "spoons" to refer to units of energy and may collectively refer to themselves as "spoonies" (Miserandino, 2003).
} 
The difficulty of getting access to care and treatment and the ongoing experience of having pain ignored or trivialized by doctors and other people in their lives can give many people with chronic pain complicated feelings about models of disability justice that are uniformly resistant to diagnosis and treatment. This is why the more nuanced approach to narratives around cure and healing that crip theory advocates for is so critical. As Andrea expresses:

[Y]ou know what pisses me off? People insisting that all disability is socially constructed. Because yes, sure, some elements of the built environment made things harder on me. And absolutely, certain social systems did me no favours. But my body fucking hurt. From the inside. In nerves and tissues. This wasn't because of building design or bigotry. It was because I had fucking cancerlong-term, long-undiagnosed, recurring. If angels had magically come and transported me to every place I needed to go, gentle as a drifting feather, I would still have been in unbearable pain. And you know what helped? Diagnosis and treatment. Like, good old-fashioned Western medicine: an MRI, surgery. When the tumour grew back, a pain clinic, and eventually another surgery, and radiation. Not a ramp or an elevator or a more anti-ableist attitude on the part of a social structure. Not pride in my disability, or a new identity as a person with a disability (though I did acquire the latter as part of the process). Just straight-up medical help. Scalpels and anaesthesia and staples. Evil death rays. I have many, many beefs with the medical system, and I had to fight some truly shitty battles to get the treatment I needed. But the end result was: it worked. (Zanin, 2018, para. 4-5)

Andrea also highlighted that some disability justice movements create a hierarchy of how individual people choose to engage with their own pain and/or disabilities:

When activists avoid discussing or accounting for pain, it feels like more than an oversight. It feels like a deliberate obscuring of an inconvenient truth that doesn't fit with the agenda. It feels like creating a hierarchy where "good" people with disabilities blame society and find pride in their difference, while "bad" people with disabilities seek treatment and cure, and wish for an end to their suffering. It feels like a turning away from the body, like so many supposedly progressive theoretical models do, as a way to seek a kind of fraught legitimacy that only functions at the price of self-denial. It's a bizarrely WASP$\mathrm{y}$, ascetic approach, and I want no part of it. (Zanin, 2018, para. 14)

As Courtney W. Bailey (2019) points out, certain branches of disability studies have inadvertently created what she calls a "disabled normate". Bailey's "disabled normate" is 
constructed through theories of disability that create hierarchies around how different individuals manage their own bodies, with "cure at the bottom, treatment in the middle, and adaptation/acceptance at the top" (Bailey, 2019). Resistance to medicalization, diagnosis, and cure is prevalent in critical disability studies literature. I am immensely sympathetic to the necessity of this resistance, and recognize it is a critical intervention in a history of exclusion, exploitation, and ableism. Diagnosis and cure can be fraught, and when a diagnosis is received, especially after a long struggle with the medical system, it often comes with intense pressure to do everything possible to pursue cure. S. Naomi talked about receiving a diagnosis and immediately aggressively pursuing a cure that remained elusive:

At thirty, when I was first diagnosed with fibromyalgia, I thought, "Fuck, I have one of those damn lesbian whiny diseases." I wanted no part of it and spent ten thousand dollars trying to find a cure for a disease no one knows the cause of or cure for. I had rarely gone to doctors before the onset of this disease. But as I found myself unable to walk or even stay awake, I went to acupuncturists, chiropractors, and deep-muscle-massage therapists. I did sleep studies and bought a c-pap and medicine, all without insurance. I went to faith healers and to witches. I ate ginseng and bee pollen. I went to endocrinologists, physiologists, rheumatologists, an osteopath, and a homeopathic doctor. I went to women who did muscle testing on me and told me I was allergic to everything. I stopped eating meat and dairy. I went to physical therapists. I was Rolfed and did Feldenkrais. I got orthotics and expensive shoes. My friend paid a person who was adept at using a divining rod to look me over. (Finkelstein, 2003, p. 310)

For S. Naomi, under compulsory able-bodiedness pursuing cure felt like the only option in the face of diagnosis. It was the next logical step and something they pursued at great personal expense. This demonstrates some of the tensions that exist around diagnosis. My own experience of diagnosis was that it gave me permission to be sick, slow down, and sit with pain, but that experience is not universal, and can also be mediated by other forms of social privilege and oppression. Crip theory creates space for these complexities, and I join many others with invisible disabilities in being hesitant about a total disavowal of medical intervention and 
diagnosis. As Samuels (2003) argues, those with invisible disabilities (including chronic illness and chronic pain) are often required to explain and justify their bodies to a "skeptical, ignorant, and somewhat hostile audience" (p. 238). For many in this position, this is even more difficult to do in the absence of a diagnosis and the validation that can come with medical recognition. In the absence of any visible signifiers of disability, I rely heavily on written documentation of my disability (dependent on diagnosis) to access supports and services I depend on. My priority seating card for public transit, for example, gives me a sense of security when attempting to find a seat on the bus. This struggle is not unique:

Many write of being denied benefits and accommodations because their nonvisible disabilities are perceived as minor or imaginary. Nonvisibly disabled people who use disabled parking permits are routinely challenged and harassed by strangers. Recently, a sympathetic nondisabled friend of mine told me that a colleague of hers had reported triumphantly her detection of someone using a disabled parking permit illegally. The colleague's conclusion was based on the fact that the woman she saw getting out of the car was young and "well-groomed" and had no sign of a limp. In addition, the colleague continued, she had followed the woman closely as they entered the building and had ascertained that she was breathing "normally" and so could have no respiratory impairments. Such constant and invasive surveillance of nonvisibly disabled bodies is the result of a convergence of complicated cultural discourses regarding independence, fraud, malingering, and entitlement; the form it takes almost always involves a perceived discontinuity between appearance, behavior, and identity. (Samuels, 2003, p. 247)

In conversations with other invisibly disabled friends, we have admitted (with some guilt) that in an attempt to avoid the shame and embarrassment that can occur when using disability supports in public (like accessible washroom stalls, accessible parking, or priority seating on public transit) when we appear "healthy" and nondisabled, we sometimes "play up" aspects of our disability when we need to use those services. This can look like an over-exaggerated limp, intentional instability, or a more obvious struggle to stand. This is not to say that our accommodation needs are not legitimate, but rather that we feel the need to perform a certain 
stereotype of disability to justify our use of necessary supports. Samuels (2003) writes of one example where a legally blind friend became "so oppressed by [the] refusal to respect her assistance dog's status, that she began to use a white cane she did not need". This is exacerbated in a culture that operates under structurally-imposed resource scarcity under capitalism. Under this framework, people are often portrayed as though they are in competition for limited resources, and thus must prove that they are adequately "deserving" of accommodations. This reinscribes the idea of disability as an individual problem to be accommodated on a case-by-case basis. All of this contributes to systems of power that delegitimize or minimize the experiences of people with chronic pain and other invisible disabilities. A critical crip understanding of diagnosis must embrace the disparate and often contradictory individual experiences of diagnosis while also challenging underlying structures and systems that produce inequities in health care access and disability supports. This is only possible through a sustained challenge to compulsory able-bodiedness that values disabled people as knowledge-producers.

Epistemic injustice ${ }^{17}$ as defined by Fricker (2007) refers to the ways an individual or community can be wronged in their capacity as a knower. Epistemic injustice can be a site of significant harm, as the ability to be understood and believed when narrating our own experiences is a central component of identity, agency, and dignity (Kidd \& Carel, 2017). Epistemic injustice, then, is often conceptualized as being at the heart or a driving force behind social justice issues. People living with chronic illnesses and chronic pain, especially when their symptoms are predominantly invisible and difficult to measure, are particularly vulnerable to epistemic injustice. According to Ian James Kidd and Havi Carel (2017) persistent stereotypes of

\footnotetext{
${ }^{17}$ Epistemic injustice is an umbrella term that hermeneutical injustice falls under. While I am focusing on hermeneutical injustice specifically, a lot of the existing bioethics research that I rely on refers more broadly to epistemic injustice, so that language will be used when I am referencing bioethics research.
} 
chronically ill people "tend to connote incapacitation, disability, diminished agency, social vulnerability, psychological fragility, and bodily failure, among others. These stereotypes often portray illness in terms of moral or conative failure or social defect that may 'contaminate its surroundings"” (p. 176). These stereotypes influence how others interact with chronically ill people and predispose them to a status of being epistemically unreliable (Kidd \& Carel, 2017). In some cases, the epistemic injustice can arise from well-intentioned people who simply lack the necessary experience to relate to another person's pain, but they can also arise from power structures that use a deliberate lack of understanding to reinforce existing hierarchies. Within an ableist system, there are many examples where "a particular social group actively benefits from their inability to understand, and hence take seriously, the experiences of other groups. Bacon's maxim that knowledge is power is true, but in certain contexts ignorance can also be a source and means of legitimating power" (Kidd \& Carel, 2017, p. 183). The interpretation of another person's experience will also be shaped by the existing biases of the observer:

[T]he processes of naming pain conditions, diagnosing patients, and determining appropriate interventions, even when employed by experts, are valueladen...Healthcare providers' social environment, personal background, worldview, and other values also influence how they observe their patients' symptoms, how they investigate and interpret their histories, what diagnoses they offer for reported and observed symptoms, and what among the increasing number of treatment options they recommend. It is within this complex combination of social and institutional structures, historical and economic realities, medical advances, as well as power relations that medical experts define issues and goals. (Buchman et al. 2017, p. 33)

The values and structural assumptions of Western medicine ascribe value to measurable and objective "truths" that can be observed in a clinical setting. Chronic pain often challenges this understanding of the human body (Buchman et al., 2017). The absence of a pathology that can be measured and clinically observed leads to "metaphysical doubt regarding the existence of the illness itself" (Buchman et al., 2017, p. 34). This is further exacerbated by the fact that the 
burden of chronic pain is typically higher for people with multiple marginalized identities, as "already-disadvantaged groups are increasingly likely to have their pain delegitimized and doubted" (Buchman et al. 2017, p. 37). Marginalized identities including women, children, LGBTQ+ people, and racialized people can have an intensified experience of epistemic injustice due to the double marginalization that occurs at the intersections of their identities and experiences of pain and illness (Buchman et al., 2017). This structural erasure of the lived experiences of people living with chronic pain is further exacerbated by the political consequences of not recognizing the pain of others. As Scarry (1985) argues:

The relative ease or difficulty with which any given phenomenon can be verbally represented also influences the ease or difficulty with which that phenomenon comes to be politically represented...It is not simply accurate but tautological to observe that given any two phenomena, the one that is more visible will receive more attention. But the sentient fact of physical pain is not simply somewhat less easy to express than some second event, but so nearly impossible to express, so flatly invisible, that the problem goes beyond the possibility of almost any other phenomenon occupying the same environment that will distract attention from it. Indeed, even where it is virtually the only content in a given environment, it will be possible to describe that environment as though the pain were not there. (p. 12)

The notion that pain is unsharable is often taken further by stating that pain destroys language (Scarry, 1985). We may attempt to describe pain using descriptive words like "stabbing", "burning", "aching", or we may rank it on a scale of 1-10, or compare it to another painful experience we believe the listener may have also experienced and thus be capable of relating to and understanding, but we can never truly communicate the lived and embodied experience of our pain with another, because it is always subject to their own interpretive lens. While I think Scarry's contribution to the theoretical landscape of chronic pain is invaluable and agree that pain is unsharable in many contexts, as previously stated, I agree with Patsavas that much of the unsharability of pain, anchored in abjection, is framed in structural and social conditions that can be overcome where those conditions are adequately challenged. There is nothing innately 
unsharable about the embodied experience of pain, but rather the unsharability comes from the cultural creation of people in pain as abject subjects whose lives are perceived as less worth living. I am also somewhat in agreement with Stan van Hooft (2003) when he argues that Scarry's interpretation is an oversimplification of the experience of pain:

[T]here is nothing unusual about experiences having to be described in metaphors. Try describing the beauty of a sunset without using them. That one needs metaphors here does not imply that the experience is radically private, incommunicable, or unsharable...[A]ll experience is inherently unsharable in some sense. It is in the nature of experience, being subjective, that it is the experience only of the experiencer. As such it is not shareable. It cannot be another's experience. You cannot make another feel a pain by talking about it. (p. 257)

In other words, metaphor is not necessarily any more inadequate for explaining pain than it is for explaining any other experience. If someone describes their pain as "piercing", most people can imagine what it would feel like to have something piercing their skin (van Hooft, 2003).

Returning to Scarry's argument that pain destroys language, it may be true that in extreme examples of pain (such as the case of torture, which Scarry's 1985 work, The Body in Pain, primarily referenced) people may lose the ability to speak or articulate their pain using spoken language. That does not mean, however, that they are not communicating their experience of pain to those around them. A person in extreme pain can still grimace, cry, scream, or move their body in ways that communicate that they are in pain. "It is difficult to imagine a more eloquent expression of pain and a more effective communication of its cruelty than a cry of distress. That language is unable to convey this verbally does not mean that it cannot be conveyed at all" (van Hooft, 2003, p. 258). The problem does not lie with the person in pain's inability to communicate their pain, but rather in those around them not having the ability to witness it or share in that experience of pain in a meaningful way. 
Much of Scarry's argument is also based on the idea that language is inadequate to describe pain because language exists to refer to objects, and pain is not an experience that can be connected to objects in a meaningful way. Darren Langdridge (2007) explains this concept further when he states that "since pain is not intersubjective - being uniquely private - it is not part of the lifeworld. As such, pain represents experience that is not shared - not turned out on the world - and therefore not readily accessible to others" (p. 94). van Hooft (2003) further argues that part of the function of language is "to express ourselves in an intersubjective world" (p. 259). Much of our communication in our daily lives exists to maintain intersubjectivity, to be social, and to nurture and build community. With this in mind, part of the challenge of pain is its ability to isolate and cut people off from their social life. As Ahmed (2006) pointed out, people who do not live with chronic pain often go through their days without paying a significant amount of attention to the individual parts of their body. They move without consciously thinking of the individual movements, breathe without actively choosing to do so, and generally do not consciously think of their bodies unless something specifically provokes them to do so.

Chronic or acute pain disrupts this process by forcing the person in pain to constantly think about the parts of them that hurt and engage with their body, sometimes to the detriment of their engagement with the world around them.

Healthy and pain-free persons are able to transcend themselves into the world and project their subjectivity in such a way as to invest the world with meaning. Moreover, such persons are able to relate to others by reaching out to them in an encounter in which they lose themselves to a degree in the reality of the other and of the relationship. But persons in pain withdraw into themselves. For them, in proportion to the severity of their pain, their world reduces to their own isolated reality. The world ceases to engage such persons. They are not able to forget themselves and be fully in the world. They are not able to throw themselves into relationships with those around them and partake of the common subjectivity characteristic of social existence. Their pain crowds out all other interests and commitments. Their attention is focused upon themselves. They are obsessed with the states of their own bodies. It is not just that their experience is their own or 
that it is unsharable. All subjective states are like that. It is not that they do not have the words to express or describe their pain as others have argued. It is that they are not able to escape the prison of self-involvement which their pain has created around them. (van Hooft, 2003, p. 259)

As mentioned, Ahmed (2006) further develops these arguments in Queer Phenomenology when she argues that the body is often forgotten in day-to-day life, but pain returns focus to the body. In Ahmed's view, while pain can force focus inward and away from sociality, pleasure can be a way of simultaneously connecting with your own body and being receptive to another. Of course, this view of pain and pleasure as dichotomous is more complicated in BDSM, but Robin Bauer (2014) directly addresses how BDSM can challenge the inward focus of chronic pain when he states:

[i]ntense sensation in this context may, therefore, also lead to orienting and opening one's body toward the person inflicting the pain, welcoming the pain as well as the liminal, boundary-shifting state this paradoxical situation entails and transforming it into something pleasurable or experiencing the simultaneities of pleasure and discomfort. (p. 166)

This highlights that pain may be experienced differently in interrelational settings, and sets the context for chapter three, which will explore BDSM as a site of interdependence that can result in thinking pain otherwise. Using autoethnography and other first-person narratives, throughout this chapter I have demonstrated that people who live with chronic pain are used to hearing that their pain is not real—an experience of hermeneutical injustice — and rarely get to experience environments where their pain is acknowledged, welcomed, or witnessed. I have argued that existing theories of pain often attempt to create universal narratives of how pain is experienced, and challenged this by arguing that we can embrace the complex and diverse realities of pain and suffering while still uniting around the idea that lives lived in pain are not less worth living. This same argument can be extended to discussions around diagnosis within critical disability studies. 
Diagnosis is complicated and controversial, but a total disavowal fails to recognize the complexities of invisible illness. This also reemphasizes my epistemological position that people with chronic pain must be considered legitimate knowledge producers. I have also argued—in alignment with theorists like Patsavas (2014) and van Hooft (2003) - that pain is not necessarily inherently unsharable, but instead it is an experience that lacks a receptive social context that embraces it. With this understanding, it is easy to understand how having a space that welcomes pain could in turn challenge the unsharability of that pain, and I hypothesize that this is at least in part what can make BDSM a transformative practice for people with chronic pain. The hermeneutical injustice of having their pain ignored or denied is countered by the experience of participating in a BDSM scene where they are met with a receptive audience to their pain, and their pain thus becomes part of an interdependent relationship. It is these ideas that will be further explored in chapter three. 


\section{Chapter Three: Critical Futurity, BDSM and the Disabled Body}

Pain complicates disability studies. Pain challenges the social model's assertion that disability is entirely about social norms that fail to adequately accommodate different bodies, and it troubles notions of desiring disability. In various attempts to reckon with pain, disability studies has often fallen into the trap of trying to universalize a single experience of pain to make it politically useful. In alliance with the Crip Technoscience Manifesto ${ }^{18}$ (Hamraie \& Fritsch, 2019), I call instead for an embrace of the contradictions and complications that pain can introduce into disability scholarship. Instead of attempting to find one story of pain, it is possible to recognize a multitude of potentially conflicting experiences of living with pain and sustain a united political focus that pain in all its messiness can coexist with a life worth living. BDSM provides a space where pain can be seen and acknowledged as something we can play with, engage, and disrupt. It is not a space where pain is erased or minimized, nor is it a space where pain is catastrophized. It is a space where pain is.

In this chapter, I will provide a brief overview of existing literature on chronic pain and BDSM before offering an analysis of my data. Two major themes - control and consentpredominate earlier literature on the topic and also emerged in my data, so I will briefly discuss those themes to connect my work to existing research. However, I will primarily focus on two additional themes I observed that have not been as prominent in previous work: interdependence and thinking pain otherwise in the context of desiring disability. I will bring these ideas together

\footnotetext{
${ }^{18}$ The Crip Technoscience Manifesto, written by Aimi Hamraie and Kelly Fritsch, recognizes that complexity and messiness will always be a part of disability justice, and calls for movements to resist independence and productivity as benchmarks for a meaningful and worthwhile life (Hamraie \& Fritsch, 2019).
} 
in the context of queer utopia to argue that BDSM can be useful for engaging with pain in ways that create space for hope and collectivity alongside complexity and suffering.

As previously mentioned, a productive understanding of pain in critical disability studies must first resist the temptation to provide a sweeping understanding of how pain is experienced in individual bodies and shift its focus instead to the political and social understandings of pain that contribute to marginalization. The idea that pain can be experienced in a range of different ways, even by the same person, is central to understanding relationships to pain in the context of BDSM.

\section{Understandings of Pain in BDSM}

The idea of pain as undesirable outside of productivity can make BDSM and kink difficult to understand for people outside the community. Bauer (2014) argues:

[W] hat we culturally define as pain is often unexpected, or at least unwelcome (as in pain from surgery or chronic illness), and, therefore, it is an unpleasant and sometimes even negating experience. It is not pain in this usual sense that BDSM practitioners seek out, but carefully selected sensations in a specific context that prepares them for the stimulation and gives the sensations a different meaning from ordinary pain. (p. 166)

What Bauer is building on is the idea that the pain experienced from BDSM is different than the often-uncontrollable pain that can accompany chronic illness. Although research in this area is fairly minimal, there has been some literature that examines how pain is understood in the specific context of BDSM. In their analysis of theories of pain in BDSM, Cara R. Dunkley et al. (2019) identified prominent theories that exist in current literature. They stated that:

(1) pain enhances feelings of helplessness and submission; (2) pain creates sensation contrast so that it intensifies feelings of pleasure; and (3) pain is challenging, and the endurance of pain promotes feelings of achievement and pride. Other highly endorsed reasons reflected the functional utility of pain, 
including its ability to help participants forget the daily stresses of life and relieve emotional pain. (p. 4)

Staci Newmahr (2010) also theorized on motivations for pain play in BDSM, and came up with four primary explanations: transformed pain is pain that is instantly reframed in the brain and thus experienced as not painful, but actively pleasurable; autotelic pain is pain that is enjoyed for its own sake, so the person is experiencing the sensation as pain, but still enjoys the sensation; sacrificial pain is pain that is felt as pain and not enjoyed, but is something the submissive puts up with as a form of sacrifice (such as for punishment, which is often a component of BDSM play); investment pain refers to pain that is experienced as unpleasant but seen as valuable in service to a larger goal, such as a sense of pride at having endured the pain, or a sense of having made a Dominant proud. Newmahr also highlights that for some submissives and/or masochists, the prospect of pain in a scene may be anticipated with excitement, which can encourage a positive relationship with pain that directly impacts how pain is processed in that context (Newmahr, 2010). As these theories make clear, there is not one universal explanation for what draws people to pain in the context of BDSM, and this can be even more complicated for people who already live with chronic pain. While I will expand on these ideas throughout this chapter, I first want to briefly touch on some of the limited research that currently exists on the connections between BDSM and disability more broadly.

\section{BDSM and Disabled Sexuality}

Disabled people of all genders struggle with being presumed asexual. Until the 1990s, academic discussions of sex and disability almost exclusively focused on the physiological sexual functioning of heterosexual men with spinal cord injuries. More recently, a slow shift has begun towards an analysis that includes a broader range of disabilities, women, LGBTQ+ 
individuals, and non-normative sexual practices (Shuttleworth, 2012). Earlier disability activism also often shied away from discussions of sexuality, instead focusing primarily on issues of physical access in the public sphere. Russell Shuttleworth challenges the narrow rights-based focus and provides a succinct quote from one of his interview subjects: “I don't give a flying fuck about the ADA [Americans with Disabilities Act] because that's not gonna get me laid!" (Shuttleworth, 2012).

Abby Wilkerson (2012) builds on the idea of expanding our understandings of sex and disability to include non-normative sex. She argues that conservative sexual norms result in a doubling-down of oppression for disabled people who have non-normative sexual interests. Stephanie Tellier (2017) highlights that while advances have been made in recent years in the understanding that disabled people have sexual and emotional needs and desires, there is still limited engagement with or understanding of sexual diversity within the disabled community in academic literature. The ongoing presence of BDSM in the DSM-5 can result in even further pathologization among a population that is already often pathologized. The inherent pathologization of disabled sexuality is also already present within the DSM-5, as Tellier (2017) points out:

[T]he DSM-5 defines a paraphilia as being the sexual interest outside of " [...] genital stimulation or preparatory fondling with phenotypically normal [...]" partners (p. 685). This wording has a significant impact on the ideology of sex being a whole body experience beyond genital stimulation. For certain individuals with disabilities, penetrative and genital focused sex may not be possible. Their sexual development may lead them to explore other sexual activities and erogenous zones of the body, which in turn could consist of a paraphilia under the DSM-5. In addition, to limit sexual interests to 'phenotypically normal' individuals causes additional concerns regarding persons with visible disabilities. It becomes problematic in defining what the 'normal' appearance of a human should be, and therefore the ideology of 'normal' sexual attraction. If the DSM appears to pathologize alternative sexualities in 'normative' ablebodied persons, it completely negates the 
possibility of a 'normative' disabled sexuality. (p. 487)

Tellier further argues that the combination of cultural norms that suggest that sex and disability are incongruous and the stereotype that both BDSM and degenitalized sexuality are pathological can lead to distress, stigma, and a lack of access to compassionate health care for disabled people who participate in BDSM:

In this unique population, there may exist both overt and covert marginalization, where alternative BDSM sexual practices are misunderstood and criticized. At the same time, there is no consideration of the sexuality of persons with disabilities. In either case, this prohibits the exploration of the individual's sexuality and needs. Academia should begin to promote new research and development in a variety of sexual practices within the disabled population. To better understand and validate BDSM and disability, is to better understand holistic and creative sexualities that are already being discussed and afforded to their able-bodied counterparts. Again, in a society that has become more liberal on its sexual views, there is still a dark blanket covering disabled sexuality where only in narrow confines is it examined or even accepted. (Tellier, 2017, p. 491)

Despite these pathologizing narratives, disabled adults who participate in BDSM have noted that the advanced levels of communication and negotiation that are considered standard practice in BDSM scenes made it easier for them to advocate for their needs and ensure their disability was accommodated in a way that was safe and comfortable (Kattari, 2015). In Shanna K. Kattari's study, some disabled participants stated that they now choose to only enter sexual relationships with people who identify as kinky, as they have found that in vanilla relationships their partners are less receptive to hearing about their needs, and less creative with their accommodations (Kattari, 2015).

In examining the connections between BDSM and disability, Dawn Reynolds (2007) argues that kink can be a productive site of empowerment. She points out that BDSM directly challenges the transient boundaries between pain and pleasure, an experience that is likely 
familiar for those with chronic pain. She also argues that BDSM communities are rooted in practices of clear communication and consent that help create space for non-normative bodies. Because BDSM degenitalizes sexuality and allows for sexual expression outside of penetrative and heteronormative sex, it can provide opportunities for sexual pleasure for people whose bodies may not allow for more 'conventional' forms of sexual expression. "The relationship between disability and BDSM offers, I suggest, a key collaboration that models alternative sexual options for people with disabilities" (Reynolds, 2007, p. 40).

Kattari (2015) noted that several people with chronic pain in her study on BDSM and disability reported that receiving "good" pain via BDSM significantly reduced their "bad" pain caused by their illness or disability. Tellier (2017) also examined some of the benefits of BDSM for disabled people and included a section on chronic pain. She highlighted that BDSM has the potential to reeroticize pain and the body; that it can release endorphins that block pain signals; and that voluntary pain can distract from involuntary pain. She also emphasized the difference between "hurt" and "harm" in the BDSM community:

In BDSM, there is a concept of 'hurt not harm', where pain (hurt) can be desirable. This idea confronts the notion that pain is always negative, and redefines the construction of pain where if an individual is not averse to it, it is not really pain. This concept is not entirely new, as often times athletes experience 'good' pain after a workout; however, the idea of 'good' pain during sexual activity seems absurd. (p. 489)

Returning to Reynolds (2007) who discusses performance artist Bob Flanagan, ${ }^{19}$ she writes that "through various tortures, Flanagan was able to gain physical and psychological control over a body that was frequently out of control. Flanagan's self-imposed restrictions and degradations

\footnotetext{
${ }^{19}$ Bob Flanagan was a performance artist with cystic fibrosis. His work often centred around chronic pain and BDSM, and his relationship with his Domme and life partner Sheree Rose (Smith, 1996).
} 
served as an entertaining way to keep his reckless, unpredictable body in line” (p. 43). Sheppard (2019) recently completed the most relevant study to date on the experiences of people with chronic pain who also participate in BDSM. Based on her research, she determined that

the difference between the experiences of chronic and kink pain can be broadly thought of as experiences of involuntary but expected chronic pain, and experiences of chosen, expected pain. Chosen pain, in the case of the participants, came from deliberate, consensual, kink play; it was expected in that they engaged in their preferred practice (such as flogging or caning) knowing beforehand that they would experience pain as a result...Chronic pain, however, is not consented to but it is also not unexpected-it is pain that has been experienced for some time, and is expected to continue for an unknown duration. (para. 16)

As Sheppard further argues, part of compulsory able-bodiedness is the idea that we should seek to avoid pain as much as possible or get rid of it as quickly as possible when it does occur. The demand that pain be controlled is part of a larger process of expecting disabled people to conform to normative understandings of health and wellness. Deliberately engaging in more pain in the context of BDSM while already living with chronic pain can be disruptive to compulsory able-bodiedness by rejecting the aspiration of being pain-free (Sheppard, 2019).

As mentioned, Sheppard's new research on chronic pain and kink highlights that for people with chronic pain, BDSM can provide a sense of consenting to pain and therefore having control over it. Sheppard (2019) found that

in using pain within their play, participants were able to engage emotionally with their pain, and with their bodily selves, in a controlled space, and in ways in which they were in control, rather than relying on the judgement of medics or caregivers. This is because in kink, they had the ability to decide how they received pain, and to call a stop to any activity — as well as the knowledge that the pain is temporary. (para. 28) 
Ideas around control and consent certainly came up in the discussions of BDSM and chronic pain that I analyzed as well. In our interview, Sam talked about the distinctions they see between their chronic pain and the pain they seek out in the context of BDSM:

They're very different for me for sure. The thing with impact play and with kink is it's something that you've opted into, and you always have the chance to say "this is too much, I can't deal with it." Or if it ends up lingering more than you thought it would or you have a drop from it you can request help from whoever was in that scene with you. Whereas fibro ${ }^{20}$ is non-consensual. It's just there. They're very different sensations... The other thing I find is with kink play, you can kind of specify what kinds of pain you want. So if I'm really wanting something thuddy, or something that's going to leave an ache for a long while, or I want something sharp or stingy then I can negotiate and request that specifically and I can really sink into that mindset. Whereas the fibro is just constant, you can't turn it off and you can't even really sink into it because you know it's just going to go on until it decides to give you a break.

Sara used the language of choice when describing their experiences as well:

During [sex], I asked her to hit me. Hard. She took heated stones from the fire and burned me. She pulled my hair and held my face to the dirt. She worked her hands inside me like a puzzle. I begged for it harder and rougher, and she responded - everything informed by the many in-depth conversations we had about our boundaries, desires, and safe words beforehand. With our breath steamy in the cold air, I decided to be in pain. It was my choice, and that choice was a revelation: The reclamation of my pain made into pleasure also meant feeling autonomy within it. (Youngblood Gregory, 2019, para. 3, emphasis added)

When Sara talks about deciding to be in pain, it also returns us to the idea of "giving in" that was introduced by Piepzna-Samarasinha in the introduction. By choosing to be in pain instead of fighting against it, Sara resists normative understandings of pain as failure that posits that they should always be attempting to overcome pain. These narratives provide a useful starting point for considering the value of BDSM as a practice for people with chronic pain, and they set the context for the two other themes that emerged alongside control and consent: interdependence

\footnotetext{
${ }^{20}$ Fibro is short for fibromyalgia.
} 
(which is connected to access intimacy) and thinking pain otherwise (which is connected to desiring disability). I argue that interdependence and thinking pain otherwise position BDSM as a type of queer utopia, a potentiality of living a worthy life in the context of chronic pain.

\section{Desiring Disability and Queer Utopias}

Early in her book Feminist, Queer, Crip, Kafer (2013) asks a series of questions about cripping queer time:

What can disability studies take from queer work on critical futurity and, simultaneously, how might attention to disability expand existing approaches to queer temporality? How might our understandings of queer futurity shift when read through the experiences of disabled people, or when interpreted as part of a critique of compulsory able-bodiedness or able-mindedness? What does it do to queer time to place it alongside crip time, or queer futurity alongside crip futurity? Can we crip queer time? (Kafer, 2013, p. 27)

Visions of utopia are typically grounded in critical futurity. To explore the idea of BDSM as a potential site of queer utopia further, I will be specifically looking at José Esteban Muñoz's interpretation of utopia, which is rooted in hope and potentiality: "Queerness is essentially about the rejection of a here and now and an insistence on potentiality or concrete possibility for another world" (Muñoz, 2009, p. 1). Muñoz's work has been taken up by disability studies scholars like Kafer (2013) and Fritsch (2016b) to think critically about the future, but this work has not yet been extended to BDSM and pain, which is what I will explore in this chapter. Muñoz's polemic Cruising Utopia stands in opposition to the antirelational and antiutopian turn in queer theory that Muñoz empathizes with but simultaneously resists (e.g. Edelman, 2004). To Muñoz, the antiutopian turn and related rejection of futurity is based around principles that centre subjects who are otherwise perceived to have futures in the first place, an assumption that is not extended to racialized, disabled, or other minoritarian subjects. Hope and potentiality are 
therefore radical positions to take for those who may otherwise be seen as abject, because "minoritarian subjects are cast as hopeless in a world without utopia" (Muñoz, 2009, p. 97). He further emphasizes that the utopia he imagines is an ideal, or a "horizon of possibility" (ibid.) rather than a fixed or prescriptive vision of the world. Muñoz further argues, echoing Barthes, that the utopian is quotidian, meaning that the utopian impulse can be enacted as part of everyday life (Muñoz, 2009). This quotidian utopia exists beyond the bonds of heteronormativity and capitalism, and hints at futures on the horizon that can be reached for through small moments of potentiality. This belief in potentiality is always rooted in desire, specifically desire for a thing that is not yet here. To Muñoz, “queerness's ecstatic and horizontal temporality is a path and a movement to a greater openness to the world" (Muñoz, 2009, p. 25). This greater openness to the world also frames queer utopia as a movement towards collectivity, a distinctly interrelational approach. It is important to note that Muñoz is not advocating for an abstract version of utopia that disavows the current moment, but rather a version of utopia that takes the current moment and expands and reimagines it along temporal and relational lines that desire a different future. "Queer futurity does not underplay desire. In fact it is all about desire, desire for both larger semiabstractions such as a better world or freedom but also, more immediately, better relations within the social that include better sex and more pleasure” (Muñoz, 2009, p. 30). Muñoz resists the idea that a focus on sex and pleasure is a turn away from collectivity or political efficacy. His focus on ecstatic time centres pleasure and connection with others as a critical component of movements for liberation and freedom from oppression:

Ecstatic time is signaled at the moment one feels ecstasy, announced perhaps in a scream or grunt of pleasure, and more importantly during moments of contemplation when one looks back at a scene from one's past, present, or future. Opening oneself up to such a perception of queerness as manifestation in and of ecstatic time offers queers much more than the meager offerings of pragmatic gay and lesbian politics. Seeing queerness as a horizon rescues and 
emboldens concepts such as freedom that have been withered by the touch of neoliberal thought and gay assimilationist politics. (Muñoz, 2009, p. 32)

Muñoz's work relies on a number of vignettes and examples that illustrate his theories in more tangible ways. There are two examples he relies on that are especially useful for considering BDSM as another possible site of queer utopia. In thinking of the dance floor, Muñoz argues that it "demands, in the openness and closeness of relations to others, an exchange and alteration of kinesthetic experience through which we become, in a sense, less like ourselves and more like each other" (Muñoz, 2009, p. 66). Further, Muñoz thinks of stages (as in physical performance spaces) as "actual utopian rehearsal rooms, where we work on a self that does not conform to the mandates of cultural logics such as late capitalism, heteronormativity, and, in some cases, white supremacy" (Muñoz, 2009, p. 111). The BDSM scene can be thought of in similar ways. BDSM can function as a utopian space because it allows participants to disrupt the here and now of straight time and engage with their own bodies and the bodies of others in ways that disrupt the often isolating experience of chronic pain and reimagine it as relational: "Participants frame BDSM scenes as interruptions to everyday or 'vanilla' life and describe experiencing moments of what Muñoz calls 'ecstatic time,' which create temporal disruptions between the here and now and the then and there of past and future utopian beyonds" (Simula, 2013, p. 78). In describing ecstasy, Muñoz returns to its roots: "Ekstasis, in the ancient Greek (exstare in the Latin), means 'to stand' or 'to be out outside of oneself,' ex meaning contemplation or consciousness that is not self-enclosed, particularly in regard to being conscious of the other" (Muñoz, 2009, p. 186). The ecstasy of a BDSM scene can become a space of interrelational connection with another, a way of witnessing, sharing in, or welcoming another in the complexity of their pain or suffering, which in turn facilitates giving in to pain in ways that are cathartic rather than despondent. Returning also to Ahmed (2002), it does not depend on shared experiences of pain so much as a 
shared commitment to being receptive to it. As Madden (2019) argues: "The BDSM scene has the potential to provide those living with chronic pain with what their friends, partners, doctors often cannot. A space to conceptualize pain, to explore it, to find words for it, and to control it. It's a necessary outlet in which pain — and the people living with it—isn't immediately bypassed, but embraced" (para. 14). Jamie Rautenberg (2014) expresses a similar sentiment about BDSM scenes, arguing that they can contribute to rethinking pain "by intentionally choosing a safe place in which we give ourselves and our bodies a voice with complete and total unconditional acceptance" (para. 17). Brandy Simula (2013) further argues that BDSM scenes can function as queer utopias "by allowing participants to envision and enact - even if only within the temporal and spatial boundaries of scenes - alternative arrangements of what can and perhaps will be in relation to the organization of bodies, experiences, desires, and pleasures" (p. 89). This space to envision alternative arrangements can be a form of queer fantasy that allows participants to imagine different futures rooted in potentiality in politically useful ways. Muñoz (2009) argues that queer fantasy is connected to utopian longing, and that these two ideas can work together to enact political transformation. This is also captured by Rodríguez (2011), who says:

Without a doubt, desires for democratic morality on any scale can exist only as utopian longings, desires for something that always exists beyond the edges of what we dare to hope for. Even when they fail, and fail they must, the utopian yearnings they represent are always sexual in the best and most queer of ways: nonreproductive, perverse, multisensory, asynchronic, and full of possibility in ways that illuminate what Butler terms the "critical promise of fantasy." The critical promise of fantasy, when and where it exists, is to challenge the contingent limits of what will and will not be called reality. Fantasy is what allows us to imagine ourselves and others otherwise; it establishes the possible in excess of the real; it points elsewhere, and when it is embodied, it brings the elsewhere home. (pp. 340-341)

As these perspectives make clear, BDSM scenes can be thought of as sites of public witnessing that create space for critical fantasies rooted in potential for a different future. For people living 
with chronic pain who are accustomed to having that pain ignored, trivialized, or shamed, the utopic potential of BDSM is its capacity to welcome and witness pain and thus present alternative scripts to cultural norms that demand pain be hidden away or suppressed in favour of productivity and independence. This utopian space does not demand that the realities of suffering that can accompany pain be denied or celebrated, but rather creates necessary space to engage with the complexities of pain in ways that encourage a disruption of social norms that see pain as dehumanizing. Simula (2013) also resists that idea that utopia is about unrealistic ideals of harmony and freedom from harm, and argues that BDSM participants are not actually seeking an escape from suffering, but rather they

perceive the queer utopian beyond that scene space creates and allows glimpses of as a beyond centred on intense moments of interrelationality. They conceptualize that interrelationality as about the complex messiness of working through experiences with one another rather than some idealistic form of interrelational harmony free from conflict and chaos. (p. 94)

This perspective emphasizes that crip/queer utopia does not require a total freedom from mess, complexity, and pain; visions of utopia can exist alongside those things. The harm of chronic pain can be real, embodied, and visceral, and still not justify a social structure that devalues lives lived with pain. Queer utopia, in this context, allows for the realities of pain to exist as they are while questioning the systems of power that make those lives less worth living. The utopia we seek, then, is a utopia that welcomes our embodied experiences as they are and creates space for meaningful engagement with those realities. That engagement most effectively disrupts straight capitalist time when it is intersubjective and interrelational, and therefore centred on interdependence. 
Langdridge (2007) argues that pain produced during $\mathrm{S} / \mathrm{M}^{21}$ play is intersubjective and thus blurs the lines between internal/external and private/public. As the pain in S/M is simultaneously being inflicted (and therefore experienced) from outside the body, but also felt (and in a sense created) inside the body, the boundary between the self and other begins to disintegrate. Scarry's (1985) work primarily deals with non-consensual torture so it is not surprising that she frames this dissolution of private/public as negative. Non-consensual intersubjective pain brings "all the solitude of absolute privacy with none of its safety, all the self-exposure of the utterly public with none of its possibility for camaraderie or shared experience" (p. 53). As Langdridge (2007) points out, however, the opposite is true in consensual S/M play. The solitude of privacy is paired with the safety that comes from engaging in pain with a trusted partner (or partners), blurring the lines between private and public in ways that encourage meaningful connection rather than destroying it. As Langdridge states: "S/M and, in particular, the consensual infliction/inscription from/on one another offers up a very real and visceral way of fusing the bodily horizons of self and other: a fleshly intertwining across a divide of otherness" (p. 99). This can be thought of as a form of public witnessing that welcomes a previously solitary experience of pain into a safe space where it can be shared intersubjectively. Langdridge (2007) agrees with Scarry that pain can be particularly effective at dividing the self from the other when pain is experienced either in isolation or in non-consensual intersubjective contexts, but also argues that in the context of consensual pain, it can be uniquely effective at bridging that gap: "In $\mathrm{S} / \mathrm{M}$, bodies speak to each other, merging through the medium of pain, through the transfer of flesh and fluid, power and emotion: speaking outside language and

\footnotetext{
${ }^{21} \mathrm{~S} / \mathrm{M}$ is shorthand for sadomasochism and is used here instead of BDSM more broadly because it is the subcategory of BDSM that most explicitly deals with pain. It's also the language Langdridge uses so it is maintained for consistency.
} 
offering that rare thing, a tender moment of togetherness" (p. 101). This is also in keeping with Ahmed's (2002) previously mentioned argument that what makes the boundaries between self and other can also unmake them. While she did not expand on it further, Sheppard (2019) also hinted at this in her research when she stated: "One of the pleasures of kink was the time and space to engage with pain, as well as an audience willing to witness pain” (para. 28). This blurring between the self and other and emphasis on shared experiences highlights how public witnessing can also be a form of interdependence.

Kafer (2013)—with support from Wendell—argues that living with chronic illness or other forms of disability can create new ways of being in the world and "lead to productive insights about intimacy, relationships, and interdependence" (p. 83). A tangible example of this was expressed by Ahmed (2002) in her autobiographical account of caring for her mother while her mother dealt with severe chronic pain:

Her pleas would sometimes just be for me to bear witness, to recognize her pain. Through such witnessing, I would grant her pain the status of an event, a happening in the world, rather than just the 'something' she felt, the 'something' that would come and go with her coming and going. Through witnessing, I would give her pain a life outside the fragile borders of her vulnerable and much loved body. But her pain, despite being the event that drew us together (the quiet nights in watching classical movies, it was a life together that hummed with sentimentality), was still shrouded in mystery. I lived with what was, for me, the unliveable. Through being with her, through being so attached to her, I felt the unfeelable. (p. 23)

Connecting this idea of interdependence more explicitly to BDSM, in Alessandra Mondin's (2016) analysis of the relationship between previously mentioned Bob Flanagan and his partner and Domme Sheree Rose, she states:

Rose does not grasp nor share her partner's physical and mental pain, but she is willing to come in his direction, she is willing to take on again the role that makes him feel alive and in control through S/M's pain. It is undeniable that 
their relationship is made stronger by S/M. She is seeking an encounter with his pain, the unbearable pain of the cystic fibrosis that is killing him, through the pain of S/M. (p. 49)

While the context is entirely different, both Ahmed and Mondin are describing similar processes. They are both describing ways of intimately sharing in the experience of another person's pain and describing how this encounter with pain altered the character of that pain and deepened the intimacy of their interdependent connection with another person. They are describing situations where pain surpassed the borders of an individual body and became something that could be at least partially carried by another person. In doing so, they resist ideologies of independence, instead framing interdependence as a radical form of care.

These ideas of BDSM as facilitating interdependence were prominent in the data I collected. Similar to what was described by Ahmed and Mondin, for Lauren, BDSM was a space where they could disclose the realities of their illness and be met with a desire to share in it rather than running from it:

A cornerstone of BDSM is negotiation and consent...There's vulnerability in disclosing the details of my illness to others, and it's something I have to give even to people I'm not close with, in case of emergency. Here is what to do with my body, if I'm rendered incapable of carrying it: here is the potential risk of going on a drive, a hike, a date with me. I'm surprised every time I tell this to someone who then wants to engage with it, to bring it pleasure. I'm so tired of carrying myself that I can't imagine anyone else wanting to carry me. (Kayes, 2018, para. 21)

As Lauren expresses here, in a culture that repudiates dependence, people with pain or care needs often feel like burdens. In this context, encountering people who embrace interdependence feels transformative. As Sam further explains:

I think one thing I've really appreciated with my local [BDSM] community is having other people talk about their health as well. So I know I'm not the only person in my area who comes out to some social events who has fibro and 
participates in impact play and other kinds of pain play. And there's other folks who have like MS and stuff like I've mentioned. So that's been really nice where you don't feel quite so alone. Honestly, I think kink overall for me has been really exemplary in my life. A lot of my current friends I've met because of kink scenes or because of the kink community and I'm friends with them outside of just like "oh I like to spank you" kind of a thing. They're really supportive and understanding. I mean some of my friends who I've met through kink come over when I'm having bad health days whether it's mental or physical and they'll help me do dishes while we visit and things like that. So I mean kink has definitely added to my life and how I manage my chronic health conditions.

As Sam expresses, the larger kink community shows up in their life day-to-day as well, providing care and support as another form of public witnessing. In spaces where interdependence becomes normalized, accepting care can start to feel empowering, rather than shameful, as Ruby explains:

[A]s I was slowing down it gave me opportunity to show up in relationships in a way that I hadn't really before. I was always the doer, the planner...I set the tone for everything and there was some times when I would do so much that other people didn't have an opportunity to show up in relationship and give because it was already done. So that was another thing that changed for me because I was just so fucking tired. When you don't even want to try for pleasure or anything like that, you start to wonder like, what am I doing? And I don't want to show up in the way that I was and so I made some really pointed changes and I was quite explicit about what I could do and what I couldn't do. When I needed to rest, I could just look somebody in the eye and say I need to go lay down and that would be honoured. Which gave people a lot more opportunities to step up. And it shifted things in a really good way, a more healthy interdependent way I guess.

Returning to Lauren, the BDSM practice of aftercare was especially transformative for their understanding of interdependence and care:

Later, I spotted the woman and her partner sprawled on one of the broken-in leather couches in the main room of the dungeon. Her lashes were wet, cheeks pink, but she was wrapped in a blanket and his arms and they both looked like languid jungle cats, sated and content. It fascinated me that aftercare is normal and expected, that you can ask for whatever you need after enduring so much pain - no apologies, no need to worry that you're inconveniencing someone. Often you'll watch someone go into the dungeon in latex and heels and emerge in a pastel robe and fuzzy slippers, ready to be pampered for a while. When 
you're sick, this sort of tender, indulgent care is difficult to come by without tremendous feelings of helplessness and guilt. (Kayes, 2018, para. 20)

As Lauren succinctly summarizes in the final sentence, care takes on a different meaning when interdependence in valued. Instead of being a source of guilt or helplessness, it becomes an empowering site of intimate connection. For Xan, BDSM practice is a form of intense vulnerability and intimacy for both bottoms and tops: "I want to trust that my play partners are just as invested in holding me in my vulnerability as I am in holding them in theirs. I want the intense intimacy, the glorious pleasure, the open acceptance that comes from being witnessed, held, and met in my deep sadism" (West, 2015b, para. 41).

These ideas of care and interdependence are also intimately connected to the crip concept of access intimacy. Consider this anecdote shared by Sara:

A month after that, I met my girlfriend. On our first date, they observed my limp and wordlessly slowed their pace. We had sex that night, and as I would each time in the first year of our relationship, I cried in spurts both during and after sex. "You're safe," they told me. "I'm not going anywhere." In my girlfriend's arms, I realized queerness had prepared me for illness: This was exactly what my lovers and mentors had said to me during my very tumultuous coming out. As other friends dropped away after I came out and eventually became disabled, a legion of lesbian and queer women rallied around me at my weakest, adjusting their steps to walk alongside me. (Youngblood Gregory, 2019, para. 8)

Mia Mingus (2011) coined the term access intimacy to describe the experience of having her access needs understood and met by another person without having to explain them or request special accommodations. As Mingus highlights, access intimacy can be felt with both disabled and nondisabled people, but it is often something she experiences in the company of other sick or disabled people who have a nuanced understanding of access informed by their own lived experience. Access intimacy is not enacted out of charity, obligation, or pity, but rather out of a shared commitment to interdependence and collective care (Mingus, 2011). Further, access 
intimacy does not necessarily imply perfect access or an environment free from ableism. Instead, it is about "knowing that someone else is with me in this mess" (Mingus, 2017, para. 18). For Mingus (2017), "[t]he power of access intimacy is that it reorients our approach from one where disabled people are expected to squeeze into able bodied people's world, and instead calls upon able bodied people to inhabit our world" (para. 19, emphasis original). Access intimacy can therefore be directly connected to the idea of pain being fully seen and welcomed in the context of BDSM. For Mingus, access intimacy "has been an antidote to the pain and the extreme isolation that pound like crashing waves with no end. It has been a way to remember my magnificence and my dignity. It has been the tender balm and recognition of parts of me that most people would rather deny, avoid and pretend away" (Mingus, 2017, para. 23). Access intimacy is a tangible form of public witnessing, allowing people with chronic pain to share the vulnerable, messy realities of their pain with a receptive audience. This can be connected to the idea that disabled bodies in all their messiness and complexity are already whole, not damaged or tragic. Access under this model is not about accommodating different bodies in ways that erase those differences, but rather about welcoming those differences in ways that disrupt and challenge dominant capitalist ideologies and creating a critical futurity. In other words, "[t]o approach disabled bodies by way of wholeness marks the importance of collective, relational, and interdependent approaches to disability" (Hamraie \& Fritsch, 2019, p. 17). Framing disabled people as already whole means recognizing their inherent worth outside of productivity, and also holds space for recognizing that wholeness is messy and that "whole and broken are not opposites but rather can be held in productive tension" (Hamraie \& Fritsch, 2019, p. 17).

This differs significantly from conventional understandings of access that often rely on a checklist approach to accessibility that fails to address underlying structures and social norms, 
and often overlook the social and cultural aspects of access. Access intimacy is a form of accessible world-making that is more than ramps and ASL interpretation:

Through 'accessibility,' people are thought to gain the means of participating in or accessing something that would otherwise exclude them on the basis of mental or physical impairment, educational or class status, or gender identity. In this formulation, 'accessibility' is primarily achieved through a checklist approach accessibility is obtained when a space is barrier-free for people using wheelchairs and has non-fluorescent lighting, has gender-neutral washrooms and American Sign Language interpretation available, is free or has sliding-scale fees, has integrated a range of ways for people to participate, offers childcare, is scent-free, et cetera. As a checklist to inclusion, 'accessibility' conforms to an understanding in which difference is an individual problem to accommodate. By accommodating and including individuals in this way, the fight for accessibility draws upon and reiterates the liberal rights-based approach to social change. (Fritsch, 2016a, pg. 25)

As Fritsch points out, this understanding of accessible reinforces the notion that able-bodiedness is normal, and disability is the abnormal "other" that must be accommodated. This reinscribes the idea of compulsory able-bodiedness, the exact process crip theory aims to deconstruct. In order to embrace a crip understanding of accessibility, removing physical barriers is only part of the problem. A truly crip understanding of accessibility must also critically examine why those barriers exist in the first place and challenge the underlying structures that help create them (Fritsch, 2016a). Further, it challenges the idea that assimilation into a normative, ableist world is desirable, and instead "claims disabled life as desirable life, as life worth living, and as a difference that matters" (Hamraie \& Fritsch, 2019, p. 20). This allows for a reimagining of access not as a way of including disabled people in normative structures, but as a way of life that sees disability as a desirable part of the world rather than something to be overcome. Crip theory advocates for a vision of access intimacy in which all people are encouraged to think about access in every decision they make, thus shifting the onus of accessibility from individual disabled people and back onto the culture as a whole (Fritsch, 2016a). 


\section{Thinking Pain Otherwise}

By centring interdependence, facilitating access intimacy, and creating space for welcoming and witnessing the pain of others, radical queer BDSM practices create space for thinking pain otherwise. Ruby talked about how exploring pain in a space that felt welcoming and learning to think pain otherwise had shifted her priorities in a way that can be understood as a deviation from straight capitalist time:

It's like I can do all this stuff, but then I'm actually choosing not to because I've reached a place in my life where I can no longer ignore my basic comfort. Like if I can't be in comfort I shouldn't be sitting in front of a computer sending emails and doing random fucking shit that anybody can do like, the AI is going to be there someday and I won't even have a job that way and I don't give a fuck anymore. I want to do things that light my heart up. Or just light me up in whatever way it can. I want to see what my body is capable of and I think when I started to approach it with curiosity it's like "okay, if pain is a way for my body to express itself, how can I engage my body?" In a way that feels supportive, but also exciting.

She also explained the role of submission in her relationship to pain and embodiment:

I particularly enjoy being led through an experience. Because again my roles predominantly in life are planner, doer, mother. There are days when I just want to be told what to do or put in a place of receiving...And I have some partners who are really incredible that way... [a current partner] is so good at it too, like some days she plays dead and other days oh man, I almost feel like I've died and risen again after we've had a session. Like four or five hours and you're just like, I didn't know bodies were capable of that...It's almost agony, but there's no rush, like there's no attachment to an outcome other than like really focussing on the sensation. And when I do that I found my pain lessens significantly. It's the best pain management I've ever done.

As Ruby highlights here, her participation in BDSM not only allows her to be fully present in her body in a relational way that opens her up to new possibilities for pleasure, but it also allows her to shift out of the goal-oriented mindset that typifies straight capitalist time. This shift facilitates a move towards utopia by re-figuring desire and the disabled body within a temporal frame that 
places pain as the horizon. The radical utopia of "no attachment" to the outcome requires situating pain as a site of change that is squarely in the here and now; a critical futurity enabled by the practice of BDSM play.

Returning to the idea of pain as failure, another issue raised by Carrie (2014) related to her struggles with seeing her body as one that deserved pleasure: "Yes, sex with a disability is a tough sell, but not (just) for the reasons people assume. In my experience, the hardest part isn't convincing someone else you're desirable — it's convincing yourself that your body is worth pleasing" (para. 4). Ruby also discussed the moment she realized that she had been thinking of her intense chronic pain as a form of deserved punishment that she had to endure, and how BDSM allowed her to reframe that:

What I love in BDSM is I set the context, and taking into consideration how my body feels, I'll navigate and I'll create an experience that feels good for me. It feels empowering, and I don't feel as much in a victim state, and I felt like that for many years. Like why is this happening to me? I'm too young. None of this was my fault. Like I've had years and years of trauma which obviously have been contributing to a lot of my body's response to stress. My body has not been okay, it has not been treated well for most of its life, it's still learning ways to communicate to me that I will listen to. So I'm listening, more so, and I'm also talking back. So we're having more in-depth conversations these days and it feels better, it feels a lot better. The pain is still there, but we have a more respectful relationship where I realized that I was creating my own narrative around why the pain was coming to me, it's not a punishment. It's definitely the result of some punishments over time, but I'm not deserving of it. When I neutralize it to it being a way for my body to communicate with my mind, it's like okay, that's clear. That took a lot of the frustration, anger, resentment, and that helps me to breathe easier which helps ease my pain. All around. It wasn't until I made that big shift that my pain felt like it really was being managed better.

As both Carrie and Ruby highlight, cultural norms around pain can frame persistent pain as a form of failure. Either you did something wrong to be in pain in the first place, or you are not working hard enough to overcome it or cure it. This can result in feeling like pleasure is both 
unattainable and undeserved. Carrie (2014) discussed the moment of coming to the realization that she could be in pain and still experience pleasure, and that those experiences did not need to be mutually exclusive:

I can handle pain like a pro. It's easier for my body to feel pain than to feel good. Now, maybe I could have both.

The next time we had sex, Alex said, "close your eyes — I want to try something."

I did, but it didn't matter much, because she tied a blindfold around my eyes first thing. Then I felt my hands go up behind my head, and heard a click, click. I didn't expect handcuffs on the first try, but there they were. And then I felt the first pinch — right on my nipple. And then another on the other side.

"Is this okay?"

"Keep going."

I never asked her to stop, which is a shame, because our safeword was dinosaur and I still think that's amazing. But alas, there was no dinosaur, and when she took the blindfold off, I saw that my chest was covered in clothespins. (When you're in your twenties, nipple clamps are expensive, so you work with what you have.) I'd never seen my body look like that. She must have been pretty impressed, because the first thing she said was, "I've never been able to do that before. Nobody has been able to take that many."

It's not often (i.e., almost never) that I get told I'm good at a physical activity. But now my body, which had spent so many years letting me down and making decisions without my consent, had gone and done something absolutely right and done it better. It had done something other people's bodies, "healthy" bodies, hadn't been able to. (para. 15-18)

For Carrie in this moment, playing with pain in the context of BDSM gave her a sense of pride in her body that she had previously struggled to find. Not only were her experiences of pain not a barrier to pleasure in this context, they had actively enhanced it. Similarly, returning to Lauren's words from chapter one, BDSM provides a space for them to find joy and catharsis in pain:

I'm startled sometimes by the brightness of BDSM, the pain I opt into. On its surface it's awash in a dim red glow, all heavy chains and rubber ball gags, mistresses wrapped in PVC and breath-stealing corsets. That manufactured 
darkness is there, if you want it - and sometimes I do. But I find that I laugh during play - not a misnomer - more often than I cry, giggling when a flogger tail tickles my shoulder blade, snorting after I gasp at an unanticipated smack. The moments of humor and weirdness are normal, just as they are in sex; and just as with sex, mainstream and pornographic representations of BDSM always polish those messy, human edges away...My heart relishes the catharsis of the dark, but sometimes all my body needs is that bright edge to crack open the joy in pain. (Kayes, 2018, para. 27)

Sara takes this idea even further, arguing that for them, pleasure and connection is not just

possible with chronic pain, but actively enhanced by that pain:

When I Googled "chronic pain and sex" this morning, the Mayo Clinic told me that when "chronic pain invades your life, the pleasures of sexuality often disappear.' It says I can find my sexuality again in spite of chronic pain. That's the common tone and logic in most mainstream information about chronic pain: that it's something to conquer or work against. But what if I connect best with my body because of that pain? Despite what Mayo Clinic tells me - and despite the desexualization of disabled people, in general — pain hasn't disappeared my pleasure or invaded my life. I do not overcome or manage my pain in the hopes of 'reigniting' pleasurable sex or a connection to my body. My intense, chronic pain guides me towards queerer, kinkier, and more intimate sex-so I follow that pain willingly. (Youngblood Gregory, 2019, para. 5)

Importantly, like Ruby, they elaborated on the way that pain allowed them to shift from a mindset of performance and goal-oriented sex to a space of more immersive experiences that disrupt conventional temporal structures:

I appreciate the connected ways chronic pain deepens and expands the sex I share with others. During sex, my head used to spin from performance anxiety: How does this feel for them? Am I doing this right? Pleasure came from the relief that sex was over, or that my partner was satisfied, not from the act itself. Because of chronic pain, I now feel everything - physically, emotionally, and otherwise - through the core of my body. Chronic pain quiets my mind, offering me wider physical and sensual opportunities. These opportunities look like bottoming. Like being a pillow princess. ${ }^{22}$ Like bratty demands and, occasionally, absolute submission to my partners. Before, I thought bottoming would make me too vulnerable, that making requests for certain acts was selfish, and that my kinks were embarrassing. Now, because my mind is quieter,

\footnotetext{
${ }^{22}$ A pillow princess is a slang term primarily used for queer femmes who prefer to bottom/receive during sexual play.
} 
submission allows me an intense, prolonged focus on my body and what turns me on. Pain transformed my pleasure from background to foreground.

(Youngblood Gregory, 2019, para. 11)

Sara also considers their participation in BDSM a direct form of resistance against structural forces that devalue lives like theirs:

For me, ideal sex is always a shout of fuck you to the forces that keep queer spoonies like me down and out and in spite of. Chronic pain never meant the end of my sensuality, but its expansion into queerer, stranger, and more complicated modes. Alongside the forced expansion of my pain tolerance, I found a deep well of gratitude for my body's capacity to feel. Without chronic pain, I may have never found that fresh water. (Youngblood Gregory, 2019, para. 12)

This capacity to experience pleasure alongside pain was an important aspect of reconciling a sense of pride and desire in disability and connection to pleasure with the realities of suffering and grief. Xan highlights the reality that many people with chronic pain struggle with, which is the dissonance between wanting treatment and cure for their pain and potentially grieving the loss of function they may have once had, while also imagining futures that hold space for lives lived in pain.

For me it's about holding both pieces, together: the piece about how it's a loss to not be able to do what feels so good and important and precious to me, and the piece that's about the creativity that we all have as disabled people, as kinky people, to figure it out. To figure out a different way to do it. Both pieces are there, are part of my experience. (West, 2015a, para. 25)

This is also in keeping with Samuels' writing on crip time as grief time. To Samuels (2017), crip time is simultaneously a site of liberation and grief:

Crip time is grief time. It is a time of loss, and of the crushing undertow that accompanies loss... What I have found much harder to let go is the memory of my healthier self. With each new symptom, each new impairment, I grieve again for the lost time, the lost years that are now not yet to come. This is not to say that I wish for a cure - not exactly. I wish to be both myself and not-myself, a state of paradoxical longing that I think every person with chronic pain occupies 
at some point or another. I wish for time to split and allow two paths for my life and that I could move back and forth between them at will. (Samuels, 2017)

What these narratives demonstrate is that crip futurity can be grounded in the realities of pain and suffering without abandoning the potential that exists on the horizon. The experiences shared here acknowledge the liminal space many people with pain exist in. It is possible to want relief from the physical pain while still feeling gratitude for the disruption of straight time it provides. Holding these ideas together helps trace out potential futures on the horizon that embrace lives lived in pain as fulfilling and whole without minimizing the tangible suffering that can accompany pain. It simultaneously shifts the present moment into a space to sit with and engage with pain without focusing on overcoming it. For Xan, engaging with pain deeply and sinking into the experience instead of trying to rush through it or overcome it disrupts straight time in a way that is profoundly meaningful:

I have a deep faith that it is possible to live through an intense amount of that kind of pain, because I lived through it. Because of that, I am up for going deeply and intensely into that kind of pain, spending a good long time writhing in it. I know the terrain of it, know how it works, know it is possible to survive it. It's cathartic for me to play with that kind of pain; I can ride the waves of it along with the bottom. It gives me this deep visceral sense of control over the pain that fucked me up so deeply for so long. I can play the music of it with exquisite grace and resonance because I know that pain so very well, and know what it takes to go through it. That kind of pain moves my inner sadist more intensely than any other - that is what feeds that aspect of me on a visceral level. I know pain. That knowledge is in all of me. It's not surprising that it would feed my sadism on such a visceral level. I bet I'm not alone. (West, 2012, para. 9)

The idea of catharsis that appears in many of these narratives brings us back to the idea of giving in. Catharsis is a form of release, a way of letting go that feels transformative. In this way it is also crip time, a way of resisting normative structures of efficiency and productivity in favour of interdependence and fluid relations. It also connects to the hope that emerges from utopia. For S.

Naomi, BDSM is a way of reclaiming hope and queerness: 
When I fuck a womyn until I am sweating, for her pleasure and mine, despite the pain that I will not let steal from me this most basic piece of my queerness, I am still being the butch I have always been; perhaps even more, I am being a crippled butch. I am someone who cherishes hir $^{23}$ queerness, who refuses to assimilate or give up one inch of this precious ground we have made when there was almost no hope or give or space for us and our desires at all. (Finkelstein, 2003, p. 316)

With this in mind, I return to the issue of hermeneutical injustice. If hermeneutical injustice is “the injustice of having some significant area of one's social experience obscured from collective understanding" (Fricker, 2007, p. 159), then it follows that hermeneutical justice would be served when an individual or group's previously obscured social experience was welcomed, shared, and truly seen. In examining these existing theories of public witnessing, interdependence, and access intimacy as a way of welcoming pain and experiencing it otherwise, I argue that these approaches can be used as a form of hermeneutical justice. For some people, BDSM provides a space where their pain is not only welcomed and witnessed, but actually meaningfully shared in a way that is grounded in interdependence and deep intimacy. It is through reengaging with others in ways that bring pleasure (as per Ahmed's phenomenology) paired with a sense of having pain witnessed and welcomed that hermeneutical justice can be achieved.

Building on and responding to the concepts introduced in chapter two, in this chapter I have analyzed the major themes related to BDSM that emerged in my data and connected them to theories of queer utopia and crip/queer futurity, making the argument that BDSM in its more radical forms can be a space of interdependence that allows us to think pain otherwise and disrupt straight capitalist time. I began by providing an overview of existing literature on theories

\footnotetext{
${ }^{23}$ While S. Naomi uses the pronoun 'hir' in this quote, their most recent bio (dated after the publication of the piece this quotation is taken from) states that they use they/them pronouns, so I have used those pronouns to refer to them throughout this thesis.
} 
of pain in BDSM and the connections between BDSM and disability. As demonstrated by the first-person narratives presented here and in keeping with earlier research, the idea that BDSM provides a space where pain feels more controlled and consented to is important, but using Muñoz's theory of queer utopia and considering BDSM through the lens of crip theory allows us to further understand it as a practice that facilitates interdependence and a public witnessing of pain. This can be a form of access intimacy as described by Mia Mingus, which can create space for thinking pain otherwise and desiring disability. Further, this allows for a disruption of straight, capitalist time that embraces mess, complexity, and giving in to pain in ways that are radical and disruptive, which can help facilitate hermeneutical justice. 


\section{Conclusion}

My journey as a queer butch Jew, as a survivor of abuse and of the streets, as a mixed-race adopted person, as a fat womyn, and now as a crip has always been about being able to be in the moment of my fierce and fragile desires, ceaselessly being scared stiff that I won't be allowed to have them. Terrified that I would be killed or there wouldn't be enough or I would fail or "they" would take it away. Frequently being so petrified, just under the surface, that I hid those wants and needs so deep that I could not access them any longer. The worst had already happened, but I still lived in fear of it. Then I woke up, and I woke up in screaming pain. By sitting with it, by sitting with the fear, I am feeling my way along a path that is not cleared or lit. Bit by bit, thorough infinitesimal movement: how I am a cripbutch these days is that I am coming to understand - yes, in my body, through my ragged, beat-up body - that I can have what I am craving. Fear and pain are not obstacles to it. I live with those things, and they have not killed me. Fighting unstrategically and bullheadedly is not the path to it. Nothing that they did to me or that has happened outside me - not the streets or abuse or being poor as hell or reviled or being a crip who is poked at, invaded, pathologized, and fragmented by the medical community — has killed it. My desire is still intact. In facing my fear, I find that my passion still burns. (Finkelstein, 2003, p. 318)

A central thread throughout this thesis has been the idea of embracing the complexity and messiness of pain, and finding connection, pleasure, and hope alongside it. Bringing these ideas back to crip theory, I want to return to one of the central components: desiring disability. I begin with Price (2015) who states:

Queerness and disability occur all the time, everywhere - in moments - for everyone. And desiring disability involves affirming the ways that disability blurs the boundaries between power and abjection. In such moments scarred skin is beauty; slurred speech is music; the tapping of a cane is power. The desire approach takes the older slogan 'Piss on Pity' and flips the script of that pity onto the normate: 'Don'tcha wish you could be disabled like me?' (p. 275)

While the concept of desiring disability does not refer specifically to sex and sexuality, the idea provides a useful way of understanding the intersection of chronic pain and BDSM. As mentioned, Kafer's political/relational model of disability recognizes that a person can take pride in their disabled identity while still wishing for a cure for their chronic pain. It is in this liminal 
space that many people with chronic pain who participate in BDSM exist. They can simultaneously seek relief or reprieve from their chronic pain, while taking pleasure in pain in chosen moments. McRuer (2011) also considers the question of disabled sexuality when he asks: "But what if disability were sexy? And what if disabled people were understood to be both subjects and objects of a multiplicity of erotic desires and practices, both within and outside the parameters of heteronormative sexuality?” (p. 107). To McRuer, cripping sexuality involves pushing for other kinds of sensations and other forms of connection than what heteronormativity prescribes. McRuer also asks us to consider the ways disability has been historically at the centre of various "sex panics," and how fear of disability has been used to enforce heteronormative ideals of "charmed sex" (to borrow from Rubin). As he points out, the "abnormal individual" discussed by Foucault was positioned as a threat to public health; masturbation has often been tied to blindness or insanity; and throughout the 1980s, much media coverage of the AIDS crisis implied that "queers, addicts, and sex workers out of control would infect everyone (and essentially kill them, but of course first comes significant disability)” (McRuer, 2011, p. 109). With this in mind, it is easy to see the radical potential of desiring disability. Fear of disability is often used as a justification for sex panics, moral fears, legal policies, and social norms that shape our lives. This is often apparent in both social and legal discussions about BDSM, especially more extreme forms of BDSM, where the risk of injury, pain, or disability is used as an explanation for why the practice should be avoided, prevented, or banned. To resist this by not only arguing that disability is not something to be feared, but in fact something desirable, is to challenge these norms of compulsory able-bodiedness and heteronormativity at their core. This demonstrates that it is impossible to meaningfully change existing attitudes about acceptable sex without first challenging existing attitudes about disability. 
As previously mentioned, McRuer (2010) located compulsory able-bodiedness within industrial capitalism and emphasizes that a system of compulsory able-bodiedness is dependent on norms that suggest human worth is directly tied to productivity. In neoliberal capitalism, being "free to sell one's labor but not free to do anything else effectively meant free to have an able body but not particularly free to have anything else" (p. 371). It is this system that leaves people who cannot participate in "productive" labour with the sense that they are "useless", a burden, lazy, or otherwise lesser. This also connects to another understanding of desiring disability proposed by McRuer and Wilkerson (2003). They suggest that desiring disability also mobilizes a politicized disability rights movement that uses disability to expose the fundamental contradictions of capitalism and ableism, and engages in " practices of freedom'-practices that would work to realize a world of multiple (desiring and desirable) corporealities interacting in nonexploitative ways" (p. 14). In other words, part of desiring disability is desiring and working collectively towards a future free from the oppressive structures of capitalism and compulsory able-bodiedness. It is this sense of hope for different ways of thinking of pain, interdependence and the value of human life that is central to utopian longings, and critical to imagining crip futures. As I have argued in this thesis, for some participants, BDSM functions as a site to explore these notions of utopia by acting as a space to engage with pain differently and disrupt normative temporal structures. Within that space, hope and desire are intimately connected as interlocking processes of political reimagining. To summarize, I will return to S. Naomi and their eloquent words about the value of desire and hope in a world that considers certain lives more disposable and less valuable than others:

The beauty of desire and love in all its rawness and untamed hope still leaves my throat scratchy and dry, and it's the taste of glory. When I stopped believing I was disposable because I had lost some abilities and understood that life is not valued that way except by a corrupt society that commodifies its members as 
objects to exploit, I was a step closer to real liberation. When not one of us is disposable, we will all know something more authentic and unplumbed about freedom. We will know something much more real about love. (Finkelstein, 2003, p. 318)

When I began this research, my primary objective was to establish whether people living with chronic pain could reclaim a sense of agency and control over their body and reimagine their relationship with pain through participation in BDSM. My initial proposal positioned BDSM as a way of reclaiming pain, applying crip theory's distinct approach to challenging normativity to reimagine relationships to pain and pleasure. I anticipated that this research would find that BDSM practice could provide tools that allow people with chronic pain to reframe their relationship with pain and pleasure and regain a sense of control over their body. I proposed that consenting to certain types of pain in the context of seeking pleasure could provide an alternative association with pain that differs significantly from the non-consensual experience of chronic pain caused by injury or illness, and that this may contribute to an increased sense of agency and wellbeing.

Much of that was confirmed, but what I found stretched beyond these initial thoughts. Interspersed with stories of suffering, grief, loss, and injustice was an underlying thread of resilience, hope, and desire. With that in mind, I return to Patsavas' two questions that have guided this thesis:

- “[H]ow differently [might we feel] pain in a context where interdependence is acknowledged and valued?" (Patsavas, 2014, p. 209)

- What strategies can we use that "permit us to think pain otherwise, to produce painful new knowledge, but also to construct analyses about pain that are less 
painful, and less dangerous to those of us in pain, and, in doing so, to re-imagine our (shared, pained) futures"? (Patsavas, 2014, p. 216)

Relying on crip theory and cripistemologies of pain, throughout this thesis I have attempted to answer these questions by considering BDSM as a space where pain is welcomed in all its complexity and allowed to be fully experienced in a specifically interdependent context. At its best and most radical, BDSM allows participants to think pain otherwise and relate to it differently by "giving in" to pain. It challenges the hermeneutical injustice of chronic pain by allowing people who live with pain to express it, share it with others, and be fully seen in pain without judgement. These elements combine to create tangible moments of queer utopia as Muñoz imagines it, a space of potentiality where failure, different futures and different perspectives on pain can be imagined and explored. In this way, it becomes possible to consider the crip theory concept of desiring disability in tandem with the realities of disabled bodies, including the messy and complex realities of physical pain. In a world built around ableist notions of compulsory able-bodiedness rooted in neoliberal capitalism, the interdependent nature of BDSM creates space for both pleasure and pain to coexist in ways that challenge larger systems of oppression and power that create barriers for disabled people. The queer utopia that is always on the horizon creates space for pain and grief, hope and pleasure to coexist. To borrow from Bailey (2019): "this pain is impossible, yet here I am" (para. 4). 


\section{References}

Acker, S. (2000). In/out/side: positioning the researcher in feminist qualitative research. Resources for Feminist Research, 28(1/2), 189-208.

Ahmed, S. (2002). The contingency of pain. Parallax, 8(1), 17-34.

Ahmed, S. (2006). Queer phenomenology: Orientations, objects, others. Durham: Duke University Press.

Altheide, D.L., \& Schneider, C.J. (2013). Qualitative media analysis (2nd ed.). Los Angeles: Sage Publications.

Bahner, J. (2018). Cripping sex education: Lessons learned from a programme aimed at young people with mobility impairments. Sex Education, 18(6), 640-654.

Bailey, C.W. (2019). On the impossible: Disability studies, queer theory, and the surviving crip. Disability Studies Quarterly, 39(4).

Bannerji, H. (1995). But who speaks for us? Experience and agency in conventional feminist paradigms. Thinking Through: Essays on Feminism, Marxism and Antiracism (pp. 56-91), Toronto: Canada Scholar's Press and Women's Press.

Bauer, R. (2014). Queer BDSM intimacies: Critical consent and pushing boundaries. Basingstoke: Palgrave MacMillan.

Bochner, A. (2011). Autoethnography: An Overview. Historical Social Research. Historische Sozialforschung., 36(4), 273-290. 
Bridges, D. (2001). The ethics of outsider research. Journal of Philosophy of Education. 35(3), 371- 386.

Buchman, D. Z., Ho, A., \& Goldberg, D. S. (2017). Investigating trust, expertise, and epistemic injustice in chronic pain. Journal of Bioethical Inquiry, 14(1), 31-42.

Carrie. (2014, March 11). Know me where it hurts: Sex, kink, and cerebral palsy [Blog post]. Retrieved from: https://www.autostraddle.com/know-me-where-it-hurts-kink-cerebralpalsy-226077/

Charlton, J. I. (1998). Nothing about us without us without us: Disability, oppression and empowerment. Berkeley and Los Angeles: University of California Press.

Chude-Sokei, L., Cruz, A., Musser, A. J., Nash, J. C., Stallings, L. H., \& Wachter-Grene, K. (2016). Race, pornography, and desire: A TBS roundtable. The Black Scholar, 46(4), 4964.

Craene, V. D. (2017). Fucking geographers! Or the epistemological consequences of neglecting the lusty researcher's body. Gender, Place \& Culture, 24(3), 449-464.

Crow, L. (2010). Including all of our lives: Renewing the social model of disability. In Rix, J., Nind, M., Simmons, K., Walsh, C., \& Sheehy, K. (Eds.), Equality, participation and inclusion 1: Diverse perspectives 2nd Edition (p. 133-149). Florence: Routledge Ltd.

Dunkley, C. R., Henshaw, C. D., Henshaw, S. K., \& Brotto, L. A. (2019). Physical pain as pleasure: A theoretical perspective. Journal of Sex Research, 1-17.

Edelman, L. (2004). No future: Queer theory and the death drive. Durham: Duke University Press. 
Finkelstein, S. N. (2003). The only thing you have to do is live. GLQ: A Journal of Lesbian and Gay Studies, 9(1), 307-319.

Fricker, M. (2007). Epistemic injustice: Power and the ethics of knowing. Oxford: Oxford University Press.

Fritsch, K. (2016a). Accessible. In K. Fritsch, C. O’Connor, \& A.K. Thompson (Eds.), Keywords for radicals: The contested vocabulary of late-capitalist struggle (23-38). Chico: AK Press.

Fritsch, K. (2016b). Cripping neoliberal futurity: Marking the elsewhere and elsewhen of desiring otherwise. Feral Feminisms, 5(2016), 11-26.

George, A. (2009). Quantitative and qualitative approaches to content analysis. In Bock, M.A., \& Krippendorff, K. (Eds.), The content analysis reader (144-155). Thousand Oaks, CA: Sage Publications.

Hall, M. (2019). Critical disability studies. Retrieved from: https://plato.stanford.edu/entries/disability-critical/

Hamraie, A., \& Fritsch, K. (2019). Crip technoscience manifesto. Catalyst: Feminism, Theory, Technoscience, 5(1).

Harding, S. (1989). Is there a feminist method? Feminism and science, 18-32.

Hesse-Biber, S.N. (2014). Chapter 1: A re-invitation to feminist research. In Hesse-Biber, S.N (Eds.), Feminist research practice 2nd edition (1-10). Thousand Oaks, CA: Sage Publishing.

Johnson, M. L. (2015). Bad romance: A crip feminist critique of queer failure. Hypatia, 30(1), 251-267. 
Kafer, A. (2003). Compulsory bodies: Reflections on heterosexuality and able-bodiedness. Journal of Women's History, 15(3), 77-89.

Kafer, A. (2013). Feminist, queer, crip. Bloomington: Indiana University Press.

Kattari, S. K. (2015). “Getting it”: Identity and sexual communication for sexual and gender minorities with physical disabilities. Sexuality \& Culture, 19(4), 882-899.

Kayes, L. (2018). Unbound. Retrieved from: https://therumpus.net/2018/01/unbound/

Kidd, I. J., \& Carel, H. (2017). Epistemic injustice and illness. Journal of Applied Philosophy, 34(2), 172-190.

Langdridge, D. (2007). Speaking the unspeakable: S/M \& the eroticisation of pain. In M. Barker \& D. Langdridge (Eds.), Safe, sane \& consensual: Contemporary perspectives of sadomasochism (pp. 85-97). Basingstoke: Palgrave MacMillan.

Lindemann, D. (2011). BDSM as therapy? Sexualities, 14(2), 151-172.

Linton, S. (1998). Claiming disability: Knowledge and identity. New York: New York University Press.

Madden, E. (2019, September 25). Why chronic pain sufferers are turning to BDSM. GQ Magazine. Retrieved from: https://www.gq.com/story/chronic-pain-bdsm

McCann, H. (2016). Epistemology of the subject: Queer theory's challenge to feminist sociology. Women's Studies Quarterly, 224-243.

McRuer, R. (2006). Crip theory: Cultural signs of queerness and disability. New York: New York University Press. 
McRuer, R. (2010). Compulsory able-bodiedness and queer/disabled existence. The Disability Studies Reader, 383-392.

McRuer, R. (2011). Disabling sex: Notes for a crip theory of sexuality. GLQ: A Journal of Lesbian and Gay Studies, 17(1), 107-117.

McRuer, R. (2016). Crip. In K. Fritsch, C. O’Connor, \& A.K. Thompson (Eds.), Keywords for radicals: The contested vocabulary of late-capitalist struggle (119-125). Chico: AK Press.

McRuer, R. \& Wilkerson, A. (2003). Desiring disability: Queer theory meets disability studiesIntroduction. GLQ: a Journal of Lesbian and Gay Studies., 9(1-2).

Mingus, M. (2011, May 5). Access intimacy: The missing link [Blog post]. Retrieved from: https://leavingevidence.wordpress.com/2011/05/05/access-intimacy-the-missing-link/

Mingus, M. (2017, April 12). Access intimacy, interdependence, and disability justice [Blog post]. Retrieved from: https://leavingevidence.wordpress.com/2017/04/12/access-intimacyinterdependence-and-disability-justice/

Miserandino, C. (2003). The spoon theory [Blog post]. Retrieved from:

https://web.archive.org/web/20191117210039/https://butyoudontlooksick.com/articles/writ ten-by-christine/the-spoon-theory/

Mondin, A. (2016). Fighting pain with pain: Bob Flanagan/Sheree Rose and Catherine Opie. Graduate Journal of Social Science, 12(1).

Muñoz, J. E. (2009). Cruising utopia: The then and there of queer futurity. New York: NYU Press. 
Newmahr, S. (2010). Rethinking kink: Sadomasochism as serious leisure. Qualitative Sociology, 33(3), 313-331.

Pamich, A. (2006). Chronic pain and identity (Doctoral dissertation). Retrieved from ProQuest dissertations \& theses global (U593093).

Patsavas, A. (2014). Recovering a cripistemology of pain: Leaky bodies, connective tissue, and feeling discourse. Journal of Literary \& Cultural Disability Studies 8(2), 203-218.

Piepzna-Samarasinha, L. L. (2010, June 22). Leah Lakshmi in Sins Invalid 2009 - Part 3 of 3 [Video file]. Retrieved from: https://www.youtube.com/watch?v=tj9EeQsh4Lk

Price, M. (2015). The bodymind problem and the possibilities of pain. Hypatia 30(1), 268-284.

Rautenberg, J. (2014, November 22). Using whips \& chains to heal chronic pain [Blog post]. Retrieved from: https://www.elephantjournal.com/2014/11/using-whips-chains-to-healchronic-pain-adult/

Reinharz, S. (1992). Feminist interview research. In S. Reinharz \& L. Davidman (Eds.), Feminist methods in social research (18-45). London: Oxford University Press.

Reynolds, D. (2007). Disability and BDSM: Bob Flanagan and the case for sexual rights. Sexuality Research and Social Policy: Journal of NSRC, 4(1), 40-52.

Rich, A. C. (1980). Compulsory heterosexuality and lesbian existence. Journal of women's history, 15(3), 11-48.

Rodríguez, J. M. (2011). Queer sociality and other sexual fantasies. GLQ: A Journal of Lesbian and Gay Studies, 17(2-3), 331-348. 
Roger, K. \& Mignone, J. (2018). Living your ethics: It's not just a dusty document. In S.W. Kleinknecht, L. Van den Scott \& C.B. Sander (Eds.). The Craft of Qualitative Research. Canadian Scholars' Press.

Saldaña, J. (2016). The coding manual for qualitative researchers (Third ed.). Los Angeles, California: SAGE.

Samuels, E. (2003). My body, my closet: invisible disability and the limits of coming-out discourse. GLQ: a Journal of Lesbian and Gay Studies, 9(1-2), 233-255.

Samuels, E. (2017). Six ways of looking at crip time. Disability Studies Quarterly, 37(3).

Scarry, E. (1985). The body in pain: The making and unmaking of the world. New York: Oxford University Press.

Sheppard, E. (2018). Using pain, living with pain. Feminist Review, 120(1), 54-69.

Sheppard, E. (2019). Chronic pain as fluid, BDSM as control. Disability Studies Quarterly, $39(2)$.

Sherif, B. (2001). The ambiguity of boundaries in the fieldwork experience: Establishing rapport and negotiating insider/outsider status. Qualitative Inquiry, 7(4), 436-447.

Shuttleworth, R. (2012). Bridging theory and experience: A critical-interpretive ethnography of sexuality and disability. In R. McRuer \& A. Mollow (Eds.), Sex and Disability (pp. 54-68). Durham and London: Duke University Press.

Siebers, T. (2001). Disability in theory: From social constructionism to the new realism of the body. American Literary History, 13(4), 737-754. 
Simula, B. L. (2013). Queer utopias in painful spaces: BDSM participants’ interrelational resistance to heteronormativity and gender regulation. In A critical inquiry into queer utopias (pp. 71-100). Palgrave Macmillan, New York.

Smith, R. (1996). Bob Flanagan, 43, Performer who fashioned art from his pain. New York Times. Retrieved from: https://www.nytimes.com/1996/01/06/arts/bob-flanagan-43performer-who-fashioned-art-from-his-pain.html

Tellier, S. (2017). Advancing the discourse: Disability and BDSM. Sexuality and Disability, 35(4), 485-493.

Treede, R. D., Rief, W., Barke, A., Aziz, Q., Bennett, M. I., Benoliel, R.,...Wang, S. J. (2015). A classification of chronic pain for ICD-11. Pain, 156(6), 1003-7.

van Hooft, S. (2003). Pain and communication. Medicine, Health Care and Philosophy, 6(3), $255-262$.

Vivian, A. (2011, April 24). Hurt, power, and disability [Blog post]. Retrieved from: http://adeepercountry.blogspot.com/2011/04/hurt-power-and-disability.html

Weiss, M. (2011). Techniques of Pleasure: BDSM and the circuits of sexuality. Durham and London: Duke University Press.

West, X. (2012, May 1). Pain \& sadism: How they intertwine [Blog post]. Retrieved from: https://tgstonebutch.dreamwidth.org/1238660.html

West, X. (2015a, May 1). Being a disabled top in kink community [Blog post]. Retrieved from: https://xanwest.wordpress.com/2015/05/01/being-a-disabled-top-in-kink-community/ 
West, X. (2015b, March 1). One sadist's consent [Blog post]. Retrieved from: https://xanwest.wordpress.com/2015/03/01/one-sadists-consent/

Wilkerson, A.L. (2012). Normate sex and its discontents. In R. McRuer \& A. Mollow (Eds.), Sex and Disability (pp. 183-207). Durham and London: Duke University Press.

Youngblood Gregory, S. (2019, December 2). Chronic pain made my sex life better, not worse. Vice. Retrieved from: https://www.vice.com/en_ca/article/j5y77y/chronic-pain-andsex?utm_campaign=sharebutton

Zanin, A. (2018, May 17). Consider pain: Why the social model of disability fails [Blog post]. Retrieved from: https://sexgeek.wordpress.com/2018/05/17/consider-pain-why-the-socialmodel-of-disability-fails/ 


\section{Appendix A}

Interview Guide: Hurt Not Harm: Reclaiming Pain and Resisting Compulsory AbleBodiedness by "Cripping” BDSM

Pseudonym:

Demographic Information:

Age:

Gender identity:

Sexual orientation:

Relationship status:

Racial/ethnic background:

Interview questions:

1. How long have you experienced chronic pain?

2. What kinds of pain do you experience? (where in the body, what kinds of pain)

3. What methods, if any, do you currently use to manage pain? This can include medical interventions, at-home remedies, lifestyle, etc.

4. Do you have a diagnosis for the cause of your pain? If yes, explain the process of getting that diagnosis. If no, describe your experiences attempting to secure a diagnosis, if relevant.

5. Has living with chronic pain shaped your identity in any way? How?

6. How do other people in your life respond to your pain?

7. How long have you participated in BDSM? Did you participate in BDSM before you developed chronic pain?

8. What forms of BDSM do you participate in?

9. If you participate in pain play, how would you describe the experience of pain in BDSM compared to your experience of chronic pain?

10. Do you see a relationship between your chronic pain and BDSM? Explain.

11. Do you find BDSM beneficial to your relationship with pain?

12. Do you feel like you are in control of your body? Does BDSM change the amount of control you feel you have?

13. Do you feel welcomed with your pain in BDSM spaces?

14. Do you ever deliberately engage in BDSM practices for the specific purpose of pain management?

15. Are there other things you want to share with me about your pain, your experiences of BDSM, or the relationship between the two? 